\title{
INFLUENCE OF THE SYNTHESIS ROUTE IN OBTAINING THE CUBIC OR TETRAGONAL COPPER FERRITE PHASES
}

\author{
Jaume Calvo - de la Rosa, Mercè Segarra*
}

\author{
DIOPMA Centre, Department of Materials Science and Physical Chemistry, Faculty of \\ Chemistry, IN2UB, Universitat de Barcelona, Martí i Franquès 1, 08028 Barcelona, Spain \\ *corresponding author: m.segarra@ub.edu
}

\begin{abstract}
In this work, magnetic copper ferrite nanoparticles are synthesized by polymer-assisted sol-gel and co-precipitation methods. The obtained purity and particle size reach values of $96 \%$ and 94 $\mathrm{nm}$, respectively. Evident differences in the crystal structure have been found in the synthesized nanoparticles. A tetragonal structure is formed by the sol-gel method, while the cubic form is obtained when the co-precipitation approach is used. This work provides an experimental evidence of the formation of both phases by using the same reactants and thermal conditions, and only modifying the technical procedure. The formation and stability of each phase is analysed by temperature dependent measurements, and the observed crystal structure differences are used to propose a potential fundamental explanation to our observations based on a difference on the cations' distribution and the Jahn-Teller distortion. Moreover, different copper ferrite purity and particle sizes are found when using each of the methods. The spherical shape of the particles and their tendency to sinter forming micrometric clusters are observed by electron microscopy. Finally, the divergence in magnetization between the samples prepared by each method support our argument about the different cations' distribution and open the door to a wide range of different technological applications for these materials.
\end{abstract}

\section{KEYWORDS}

Copper ferrite; Sol-gel; Co-precipitation; Tetragonal phase; Cubic phase; Jahn-Teller distortion

\section{INTRODUCTION}

Spinel ferrites are a family of ceramic materials with interesting magnetic properties. In addition, the immense capacity to modify ferrites' properties opens the possibility to design materials with novel functionalities. The chemical composition and the crystal structure are the two main aspects that define their characteristics, which can be controlled by an appropriate synthesis and processing route ${ }^{1-4}$.

These materials can be applied in a wide range of technological applications, such as biomedicine ${ }^{5,6}$, electronics ${ }^{7,8}$ or energy storage ${ }^{9,10}$. They are increasingly gaining attention for high frequency microwaves applications ${ }^{11-14}$; their large electrical resistivity makes them unique materials due to the reduced eddy current losses that they experience at elevated frequencies.

The spinel structure is chemically represented by the formula $\mathrm{AB}_{2} \mathrm{O}_{4}$. Here, oxygen $(\mathrm{O})$ atoms form a face-centred cubic (FCC) unit cell, meanwhile $A$ are divalent cations occupying tetrahedral lattice sites $\left(\mathrm{S}_{\mathrm{T}}\right)$, and $B$ represent trivalent cations placed on octahedral sites $\left(\mathrm{S}_{\mathrm{O}}\right)$. In the case of spinel ferrites, $B$ atoms correspond to $\mathrm{Fe}^{3+}$ cations, leading to the general and well-known formulation $\mathrm{MFe}_{2} \mathrm{O}_{4}$, where $M$ is the divalent cation, usually a transition metal (such as $\mathrm{Fe}^{2+}, \mathrm{Co}^{2+}$, 
$\mathrm{Mn}^{2+}, \mathrm{Ni}^{2+}, \mathrm{Zn}^{2+}$ or $\mathrm{Cu}^{2+}$ ). Depending on the specific cation introduced in the structure, and the subsequent energy of the system, the distribution of the cations can lead to what is known as inverse spinel. An inverse spinel follows the scheme $\mathrm{A}_{1-\mathrm{x}} \mathrm{B}_{\mathrm{x}}\left(\mathrm{A}_{\mathrm{x}} \mathrm{B}_{2-\mathrm{x}}\right) \mathrm{O}_{4}$, where $x$ is the inversion parameter. In a fully inverted spinel $(\mathrm{x}=1)$ all $A$ atoms are placed in $\mathrm{S}_{O}$ as well as half of $B$ cations; the other half occupy $\mathrm{S}_{\mathrm{T}}$. In case of inverse ferrite spinel, the divalent cation is now located in $\mathrm{S}_{\mathrm{O}}$, meanwhile $\mathrm{Fe}^{3+}$ cations are equally distributed between $\mathrm{S}_{\mathrm{O}}$ and $\mathrm{S}_{\mathrm{T}}$. Copper ferrite $\left(\mathrm{CuFe}_{2} \mathrm{O}_{4}\right)$ is known to be a fully inverted spinel, but as the $\mathrm{Cu}^{2+}$ activation energy is very small when changing its position, the value of $x$ depends on the specific preparation and cooling rate ${ }^{15}$. Moreover, despite the theoretical spinel consists on a cubic structure, $\mathrm{CuFe}_{2} \mathrm{O}_{4}$ can be present in two different structures: (i) tetragonal (space group I4 $4_{1} /$ amd) which is stable at low temperatures, and (ii) cubic (space group $\mathrm{Fd} 3 \mathrm{~m}$ ) which appears above $700 \mathrm{~K}\left(427^{\circ} \mathrm{C}\right)$. The formation of the tetragonal phase is attributed to the Jahn-Teller effect ${ }^{16,17}$, which arises from the distortion of one of the axis of the octahedrons (leading to a crystal symmetry reduction) ${ }^{17-19}$ caused by the $\mathrm{Cu}^{2+}$ $\left(3 \mathrm{~d}^{9}\right)$ ions migrations to the $\mathrm{S}_{\mathrm{T}}{ }^{16,18,20}$. For $\mathrm{d}^{4}$ and $\mathrm{d}^{9}$ transition-metal ions, a spontaneous degeneration of the orbits of the neighbouring atoms - leading to a distortion from the regular octahedron - may decrease the electrostatic repulsion and thus increase the stabilization energy ${ }^{18,21}$. $\mathrm{A} \mathrm{Cu}^{2+}$ occupancy factor of 0.25 at the $\mathrm{S}_{\mathrm{T}}$ is a critical value to originate the crystal distortion 22. Nevertheless, it has been proved that both structures can coexist in a temperature range of approximately $40 \mathrm{~K}^{15,23}$. The distortion parameter $(C / a)$ in an ideal tetragonal $\mathrm{CuFe}_{2} \mathrm{O}_{4}$ is $\sim 1.06$, but it is closely related to the inversion parameter. There is not a clear criterion in literature regarding a possible change in the spinel inversion parameter during the transition. Experimental data suggests that it depends on the synthesis method, as well as the annealing and cooling rates 15,24 .

There are many different techniques and approaches which have been already used to synthesize ferrites. The oldest and simplest approach is the ceramic method, where the oxide precursors are stoichiometrically mixed and heated up to activate the chemical reaction. The major drawback of this method is the elevated needed temperature (usually above $1000^{\circ} \mathrm{C}$ ). Apart from the energy consumption problem, there is an important particle growth that limits the production of nanoparticles. Moreover, due to the difficulty to reach a homogeneous mixture of the precursors, the chemical composition of the product is not ideal. If the goal is to produce high-purity nanoparticles, wet chemical methods is an interesting group of processes with many different approaches. Some of these approaches are thermal decomposition ${ }^{25}$, hydrothermal ${ }^{3,10}$, solvothermal ${ }^{26}$, co-precipitation ${ }^{27-29}$, or sol-gel ${ }^{2,14,20}$ for instance.

In this work, copper ferrite $\left(\mathrm{CuFe}_{2} \mathrm{O}_{4}\right)$ nanoparticles are prepared by two different wet chemical methods: polymer-assisted sol-gel and co-precipitation. Both methods are accurately described, and the obtained particles are characterized from a structural and magnetic point of view. The structural difference in the obtained product is discussed, and their formation is analysed by means of temperature dependent measurements. The main advantages and drawbacks of both processes are also reviewed. 


\section{EXPERIMENTAL}

\subsection{Materials}

The metal salt precursors used for both approaches have been iron nitrate $\left(\mathrm{Fe}\left(\mathrm{NO}_{3}\right)_{3} \cdot 9 \mathrm{H}_{2} \mathrm{O}\right.$, Labkem), and copper nitrate $\left(\mathrm{Cu}\left(\mathrm{NO}_{3}\right)_{2} \cdot 3 \mathrm{H}_{2} \mathrm{O}\right.$, Labkem). The gelling agent used in the sol-gel method is polyvinylpyrrolidone (PVP, Sigma-Aldrich). In the co-precipitation sodium hydroxide $(\mathrm{NaOH}$, VWR Chemicals) has been used as a basic solution.

\subsection{Synthesis}

The polymer-assisted sol-gel synthesis of $\mathrm{CuFe}_{2} \mathrm{O}_{4}$ starts with the dissolution of a specific amount of PVP (ratio 1:1 between the $\mathrm{CuFe}_{2} \mathrm{O}_{4}$ and PVP mass) in distilled water by stirring during 2 hours at room temperature. Then, stoichiometric amounts of $\mathrm{Fe}\left(\mathrm{NO}_{3}\right)_{3} \cdot 9 \mathrm{H}_{2} \mathrm{O}$ and $\mathrm{Cu}\left(\mathrm{NO}_{3}\right)_{2} \cdot 3 \mathrm{H}_{2} \mathrm{O}$ are added to the solution and stirred for 3 additional hours. After this time, the solution is heated at $80{ }^{\circ} \mathrm{C}$ in a furnace for 24 hours. In this step, the PVP polymerizes and the gel - containing a uniform mixture of metal ions - is formed. In order to eliminate the organic gel and get the oxide material, it is heated at $250{ }^{\circ} \mathrm{C}$ until burning. The obtained product is grounded to powder before performing a final thermal treatment for 1 hour to promote the reaction and to form the ferrite. The specific temperatures used in this work are $800{ }^{\circ} \mathrm{C}$ and $900{ }^{\circ} \mathrm{C}$.

In the co-precipitation preparation of $\mathrm{CuFe}_{2} \mathrm{O}_{4}$, the precursor salts $\left(\mathrm{Fe}\left(\mathrm{NO}_{3}\right)_{3} \cdot 9 \mathrm{H}_{2} \mathrm{O}\right.$ and $\left.\mathrm{Cu}\left(\mathrm{NO}_{3}\right)_{2} \cdot 3 \mathrm{H}_{2} \mathrm{O}\right)$ are dissolved in distilled water by stirring for 1 hour. A $1.5 \mathrm{M}$ solution of $\mathrm{NaOH}$ is added dropwise until $\mathrm{pH}$ reaches a value of 10 and the precipitation starts. The solution is then heated up to $80^{\circ} \mathrm{C}$ and stirred for 1 additional hour, before cooling it down to room temperature. In order to remove the remaining ions (such as $\mathrm{Na}^{+}$or $\mathrm{NO}_{3}{ }^{-}$), the product is washed four times with ethanol and water, decanting the supernatant liquid after centrifugation at $3000 \mathrm{rpm}$ for 10 minutes in each cycle. The obtained product is then dried at $80^{\circ} \mathrm{C}$ for 24 hours. A final thermal treatment at $800^{\circ} \mathrm{C}$ and $900{ }^{\circ} \mathrm{C}$ for 1 hour is also done to form the ferrite.

The used metal salt precursors and the thermal treatment conditions have been set to the same values in both methods in order to limit their differences to the specific technical procedure, and hence allow a more rigorous comparison.

\subsection{Characterization}

$\mathrm{X}$ - Ray Diffraction (XRD) measurements have been done with a PANalytical X'Pert PRO MPD $\theta / \theta$ Bragg-Brentano powder diffractometer of 240 millimetres of radius using $\mathrm{Cu} \mathrm{K}_{\alpha}$ radiation $(\lambda$ $=1.5418 \AA$ ). The temperature dependent XRD measurements have been done from $28^{\circ} \mathrm{C}$ up to $950{ }^{\circ} \mathrm{C}$, and cooled from $950^{\circ} \mathrm{C}$ to $28^{\circ} \mathrm{C}$ at a constant rate of $60^{\circ} \mathrm{C}$ per minute. Measurements have been performed in a High Temperature Chamber Anton Paar HTK1200N every $50{ }^{\circ} \mathrm{C}$, in air (oxidant) conditions. The organic content at the end of each synthesis has been checked by Fourier transformed Infrared Spectroscopy (FT-IR) using a Spectrum Two ${ }^{\mathrm{TM}}$ from Perkin Elmer supported by Dynascan ${ }^{\mathrm{TM}}$ interferometer and OpticsGuard ${ }^{\mathrm{TM}}$ Technology. The results - which are not shown for practical purposes - confirmed that none of the samples contained organic species after annealing. Particle size distributions have been measured by Laser Diffraction (LD) in a $L S^{\mathrm{TM}} 13320 M W$ from Beckman Coulter device. Scanner Electron Microscopy (SEM) images have been taken in a Field Emission SEM JEDL J-7100. Magnetic properties have been measured in a SQUID magnetometer Quantum Design MPMS XL. 


\section{RESULTS AND DISCUSSION}

In this work, four combinations of samples have been synthesized: 2 by sol-gel method (denoted with the prefix "SG" in the following plots and discussion), and 2 by co-precipitation (named as "CP"). In both cases one sample has been heated at $800^{\circ} \mathrm{C}$ and the other at $900{ }^{\circ} \mathrm{C}$, for 1 hour. Furthermore, three replicates have been done for each of the four combinations.

After completing the synthesis, the powder samples have been analysed by XRD. The comparison of the four obtained patterns is shown in Figure 1.

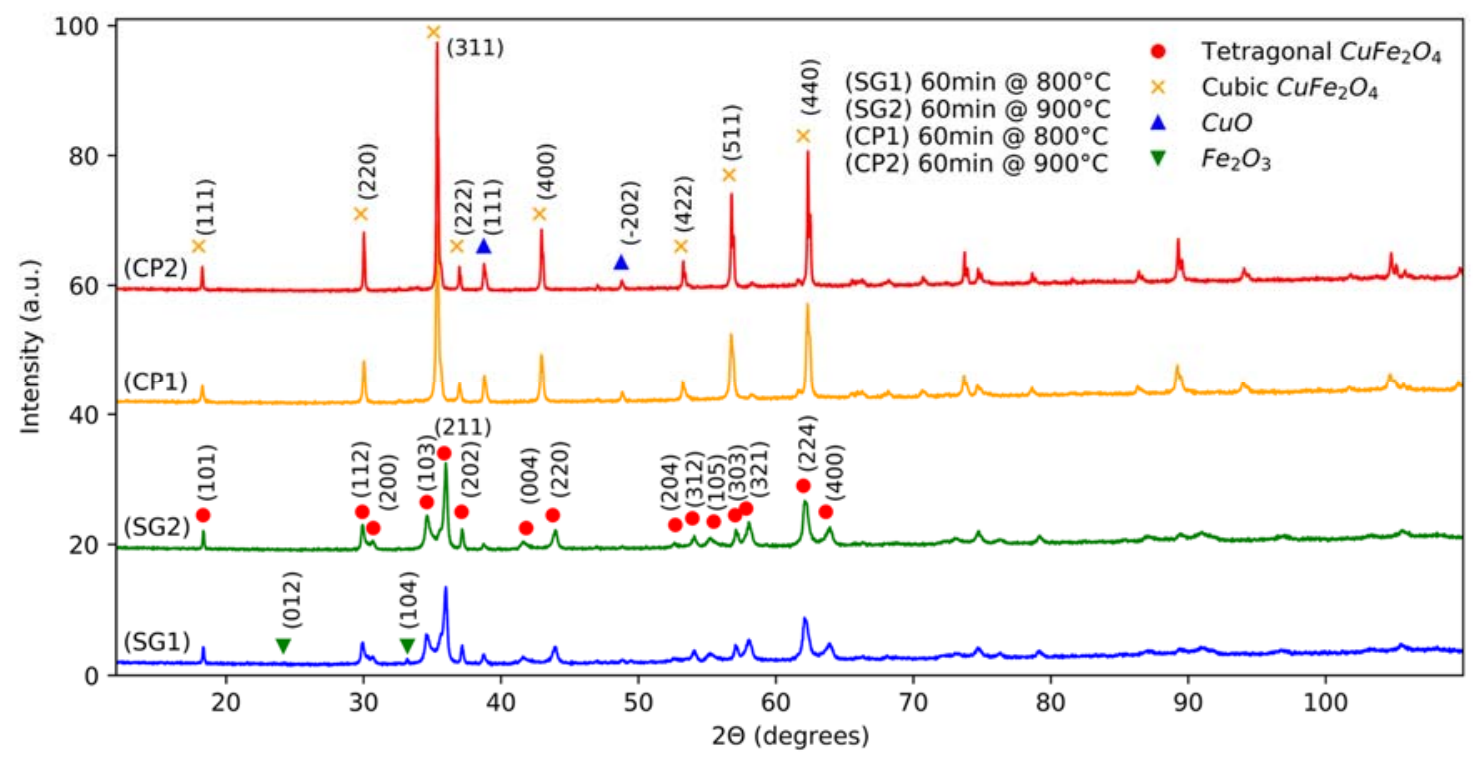

141

Figure 1. XRD patterns of the four samples. The patterns have been progressively displaced in order to facilitate their comparison. Furthermore, the Intensity (a.u.) values have been divided by a factor of 200 in order to avoid large and unmanageable quantities in the vertical axis due to the displacement. The different markers represent the main peaks of each of the four phases identified, and the values between brackets correspond to the (hkl) plane notation of each of the reflections.

Despite the low magnification in this image, it is possible to differentiate two types of traces which are characteristic for each synthesis method. Some differences are the existence of doublets around $30^{\circ}$ and $35^{\circ}$ in the case of sol-gel samples, meanwhile those prepared by co-precipitation show a single peak in this position, for instance. There are other clear differences at higher angles.

The analysis of these patterns reveals an important fact: the predominant phase in all samples is $\mathrm{CuFe}_{2} \mathrm{O}_{4}$, but it has a tetragonal structure (space group $\mathrm{I}_{1} / \mathrm{amd}$ ) in sol-gel samples, whereas it is configured in a cubic structure (space group Fd-3m) when co-precipitation synthesis is used. All samples contain traces of monoclinic $\mathrm{CuO}$, but it is more intense in the co-precipitation ones. Rhombohedral $\mathrm{Fe}_{2} \mathrm{O}_{3}$ is only detected in sample SG1.

For a clearer qualitative analysis of the presence of each phase, some specific peaks are zoomed in Figure 2. 

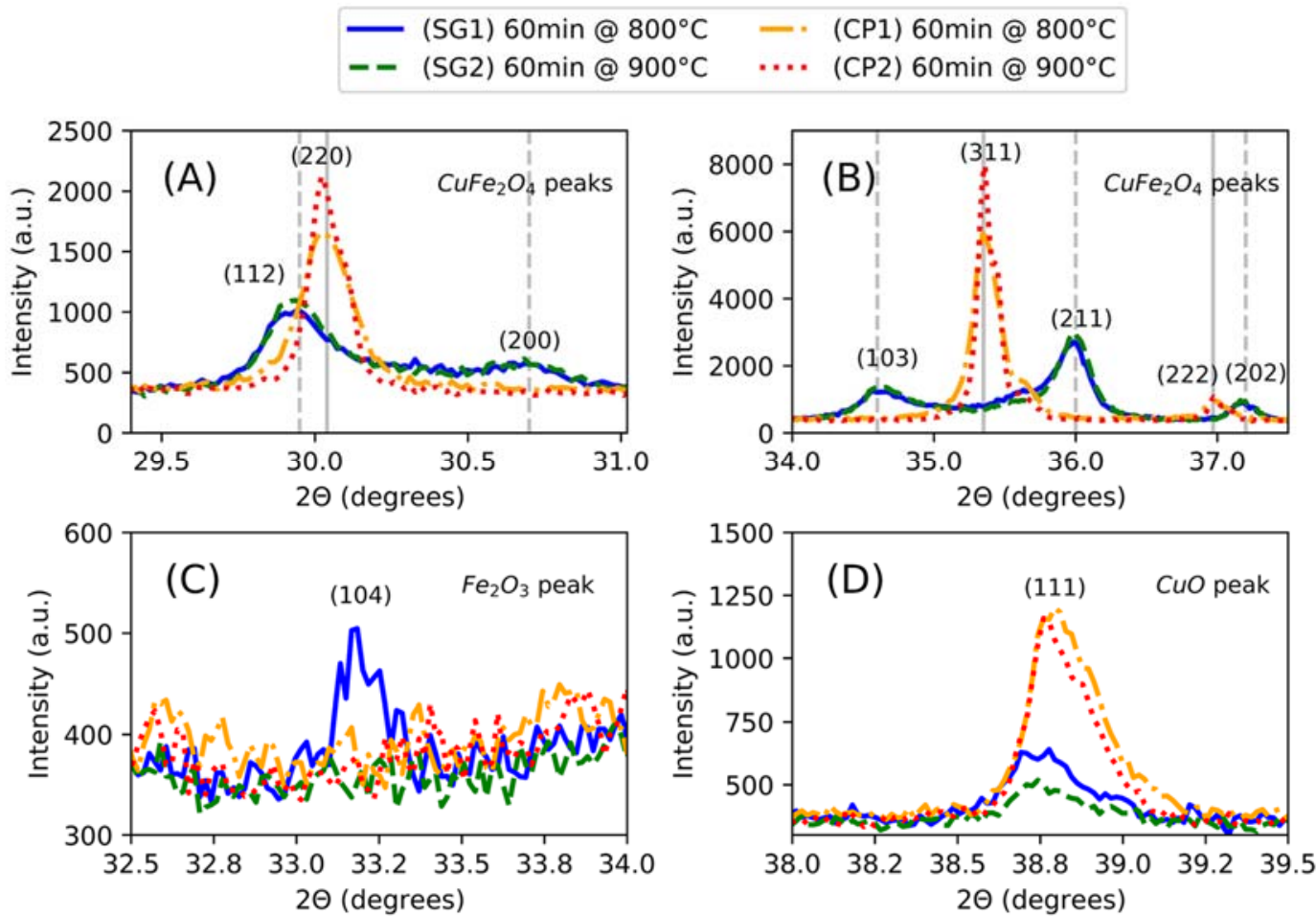

Figure 2. Zoomed regions of the XRD patterns. (A) and (B) contain different tetragonal and cubic $\mathrm{CuFe}_{2} \mathrm{O}_{4}$ peaks, (C) contains the (104) $\mathrm{Fe}_{2} \mathrm{O}_{3}$ peak, and (D) the (111) $\mathrm{CuO}$ peak. Vertical continuous lines represent the $2 \theta$ positions where cubic $\mathrm{CuFe}_{2} \mathrm{O}_{4}$ peaks are expected, meanwhile dashed lines represent the tetragonal $\mathrm{CuFe}_{2} \mathrm{O}_{4}$ positions.

162 Figure 2.A and Figure 2.B represent $2 \theta$ regions where tetragonal and cubic $\mathrm{CuFe}_{2} \mathrm{O}_{4}$ peaks are present. It is clear that sol-gel samples follow the tetragonal pattern and co-precipitation ones have the cubic structure. Additionally, we notice that there is a minimum difference in intensity between sol-gel samples, whereas the $\mathrm{CuFe}_{2} \mathrm{O}_{4}$ intensity notably increases with temperature in co-precipitation prepared powders. Figure 2.C confirms that the only sample that contains $\mathrm{Fe}_{2} \mathrm{O}_{3}$ is SG1 - which disappears at higher temperatures - while Figure 2.D verifies that all the samples still contain a small amount of $\mathrm{CuO}$ at the end of the process. Additionally, the relative content of $\mathrm{CuFe}_{2} \mathrm{O}_{4}$ increases at the higher temperatures for both methods, as could be expected. In this regard, we should comment that co-precipitation samples - which have a cubic structure - have a higher amount of $\mathrm{CuO}$ impurities than those samples prepared by sol-gel.

172 Rietveld refinement has then been performed with the goal of obtaining quantitative information about the chemical composition of each sample. In Figure 3 the refined profiles of those samples prepared at $800{ }^{\circ} \mathrm{C}$ are shown, while Table 1 summarizes the values obtained for all the synthesized samples. 

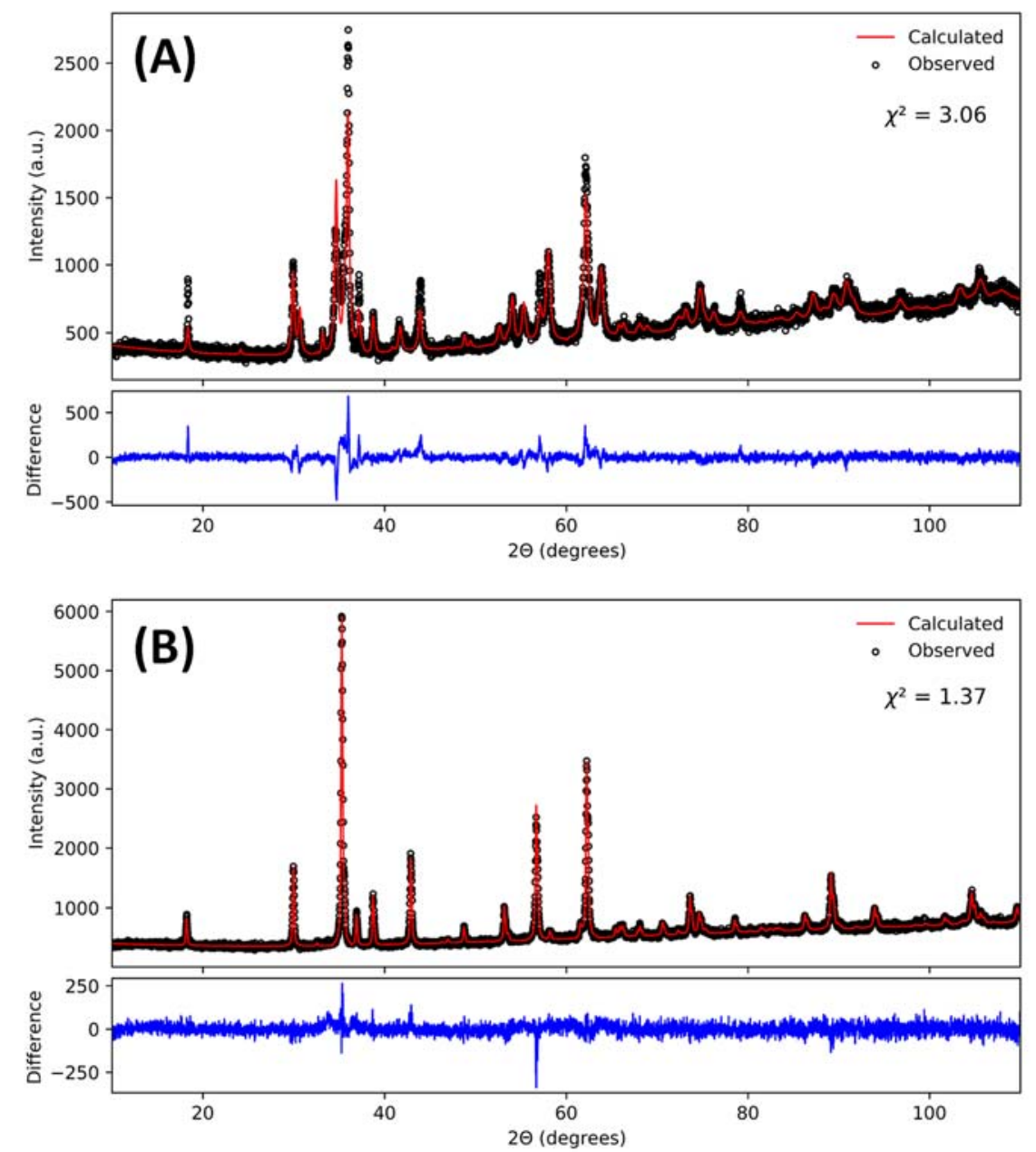

Figure 3. Rietveld refinement of the two samples prepared at $800{ }^{\circ} \mathrm{C}$, (A) SG2 and (B) CP2. Circles represent the measured data, meanwhile the continuous red line shows the calculated model. The difference between both values is represented in the bottom plot.

Table 1. Rietveld refinement compositions obtained for the four samples. " $T$ " refers to the tetragonal structure and "C" to the cubic one. $\chi^{2}$ represents the quality of the adjustment.

\begin{tabular}{cccccc} 
Sample & $\mathbf{T}-\mathrm{CuFe}_{2} \mathrm{O}_{4}(\mathbf{\%})$ & $\mathbf{C}-\mathrm{CuFe}_{2} \mathbf{O}_{4}(\mathbf{\%})$ & $\mathbf{C u O}(\mathbf{\%})$ & $\mathrm{Fe}_{2} \mathrm{O}_{3}(\mathbf{\%})$ & $\chi^{2}$ \\
\hline SG1 & 87.5 & --- & 5.7 & 6.8 & 3.06 \\
SG2 & 96.1 & -- & 3.9 & 0.0 & 3.01 \\
CP1 & --- & 88.3 & 11.7 & 0.0 & 1.37 \\
CP2 & --- & 88.4 & 11.6 & 0.0 & 1.53
\end{tabular}

184 It is confirmed, by analysing the sol-gel samples, the presence of a small quantity of $\mathrm{Fe}_{2} \mathrm{O}_{3}$ only in the sample prepared at $800{ }^{\circ} \mathrm{C}$. The purity raises up to $96.1 \%$ and the impurities reduce when increasing the temperature. These results are in very good agreement with those reported in ${ }^{30}$ for the same experimental conditions. Co-precipitation samples almost do not contain $\mathrm{Fe}_{2} \mathrm{O}_{3}$ and only an excess of $\mathrm{CuO}$ is found. The amount of $\mathrm{CuFe}_{2} \mathrm{O}_{4}$ increases with temperature as well, in good agreement with the deductions done from Figure 2. Apart from the difference in crystal structure, it should be noticed that the purity achieved by the sol-gel method is considerably higher than the one obtained by co-precipitation. 
The Rietveld method has also been used to refine the crystal structure of each of the samples. The results for the main phase $\left(\mathrm{CuFe}_{2} \mathrm{O}_{4}\right)$ are listed in Table 2. By first analysing the tetragonal samples we observe that the Rietveld refinement leads to $\mathrm{a}=\mathrm{b} \sim 5.83 \AA$, while the $\mathrm{z}$-axis is elongated to $\mathrm{c} \sim 8.66 \AA$ for both cases. The $\mathrm{c} / \mathrm{a}$ relationship changes from 1.49 to 1.48 when the annealing temperature increases from $800^{\circ} \mathrm{C}$ to $900{ }^{\circ} \mathrm{C}$. These results are in very good agreement with those previously reported by other authors ${ }^{15,16,31}$. Additionally, if we do the $\sqrt{2}$ correction on "a" and "b" to make the structure look pseudo-cubic ${ }^{15,32}$, the c/a ratio changes to 1.05 for both cases. Now, this ratio represents the distortion parameter, and the results agree with the one theoretically expected (1.06) and with those experimentally reported elsewhere ${ }^{32,33}$. On the other hand, the cell parameter for the cubic samples annealed at $800{ }^{\circ} \mathrm{C}$ and $900{ }^{\circ} \mathrm{C}$ are $8.430 \AA$ and $8.424 \AA$, respectively. Obviously, here the ratio $\mathrm{c} / \mathrm{a}=1$ as it corresponds to a non-distorted structure. Although the unit cell parameters found in literature vary depending on the specific synthesis' thermal conditions used ${ }^{15,17,31,32}$, our results fit in the reported range of values.

Table 2. Structural parameters deduced from the Rietveld refinement for each of the samples. ${ }^{*} \mathrm{c} / \mathrm{a} \sqrt{2}$ ratio provided only for tetragonal structures.

\begin{tabular}{|c|c|c|c|c|c|c|}
\hline Sample & $\begin{array}{c}\mathrm{CuFe}_{2} \mathrm{O}_{4} \\
\text { Structure }\end{array}$ & $\begin{array}{l}\text { Space } \\
\text { group }\end{array}$ & a $(\AA)$ & b $(\AA)$ & c $(\AA)$ & $\mathbf{c} / \mathbf{a} \sqrt{ } \mathbf{2} *$ \\
\hline$\overline{\text { SG1 }}$ & Tetragonal & I $4_{1} / \mathrm{amd}$ & $5.830 \pm 0.001$ & $5.830 \pm 0.001$ & $8.662 \pm 0.001$ & 1.05 \\
\hline SG2 & Tetragonal & $\mathrm{I} 4_{1} / \mathrm{amd}$ & $5.832 \pm$ & $5.832 \pm 0.001$ & $8.660 \pm 0.001$ & 1.05 \\
\hline $\mathrm{CP} 1$ & Cubic & Fd-3m & $8.430 \pm 0.001$ & $8.430 \pm 0.001$ & $8.430 \pm 0.001$ & --- \\
\hline $\mathrm{CP} 2$ & Cubic & Fd-3m & $8.424 \pm 0.001$ & $8.424 \pm 0.001$ & $8.424 \pm 0.001$ & --- \\
\hline
\end{tabular}

Recent articles studying the phase transition in sol-gel process ${ }^{20,34}$ have obtained a cubic dominant structure just after the gel calcination, which tends to disappear later at higher temperatures. With treatments in the range of $350{ }^{\circ} \mathrm{C}$ or $400{ }^{\circ} \mathrm{C}$, the cubic-to-tetragonal phase transition starts, and the tetragonal phase is completely dominant when the $\mathrm{CuFe}_{2} \mathrm{O}_{4}$ is processed at or above $800{ }^{\circ} \mathrm{C}$. Furthermore, it has been also reported that traditional ceramic synthesis working in similar temperature conditions also produce the tetragonal phase ${ }^{23}$. In this article we are working at $800^{\circ} \mathrm{C}$ and $900{ }^{\circ} \mathrm{C}$, so our results are in perfect accordance with these references. Zhuravlev et al. ${ }^{34}$ suggested that the reason why in their sol-gel samples the cubic phase remained stable after burning the gel was the fast cooling rate, which really was a quenching process and stabilized the high temperature structure. Khemthong et al. ${ }^{35}$ have recently published an interesting paper where they study the crystallization of the spinel structure during sol-gel combustion by means of in situ X-ray absorption. They conclude that, in the case of sol-gel process, the energy of the combustion may be enough to initiate the $\mathrm{CuFe}_{2} \mathrm{O}_{4}$ formation, and the subsequently calcination helps to ensure the crystallinity and phase purity. These conclusions are also in good agreement with Zhuravlev's results.

On the other hand, some previous works ${ }^{24,36,37}$ have already obtained the cubic phase by using hydrothermal and thermal decomposition routes and applying both, lower and higher temperatures compared with the transition one $\left(427^{\circ} \mathrm{C}\right)$. Furthermore, the cubic structure has also been prepared by means of solid-state reaction under $\mathrm{N}_{2}$ atmosphere ${ }^{38}$. However, there is not a clear explanation of the reason why the cubic structure is stable at room temperature instead of transforming to the tetragonal one.

Overall, in this work we are reporting an experimental evidence of the formation of the two phases by means of the same annealing conditions, cooling rates, and atmosphere conditions. In order to analyse the formation of each structure, one non-calcinated sample prepared by each method has been analysed by temperature dependent XRD. The measurements have been done during both, 
heating and cooling processes, and between room temperature $\left(28^{\circ} \mathrm{C}\right)$ and $950{ }^{\circ} \mathrm{C}$ every $50{ }^{\circ} \mathrm{C}$. Figure 4 shows the obtained diffraction patterns during the heating of the sol-gel sample. It is important to point out that, in the sol-gel sample, the gel has been burned before doing the experiment. This experience, therefore, perfectly simulates the annealing of the sol-gel obtained powder.

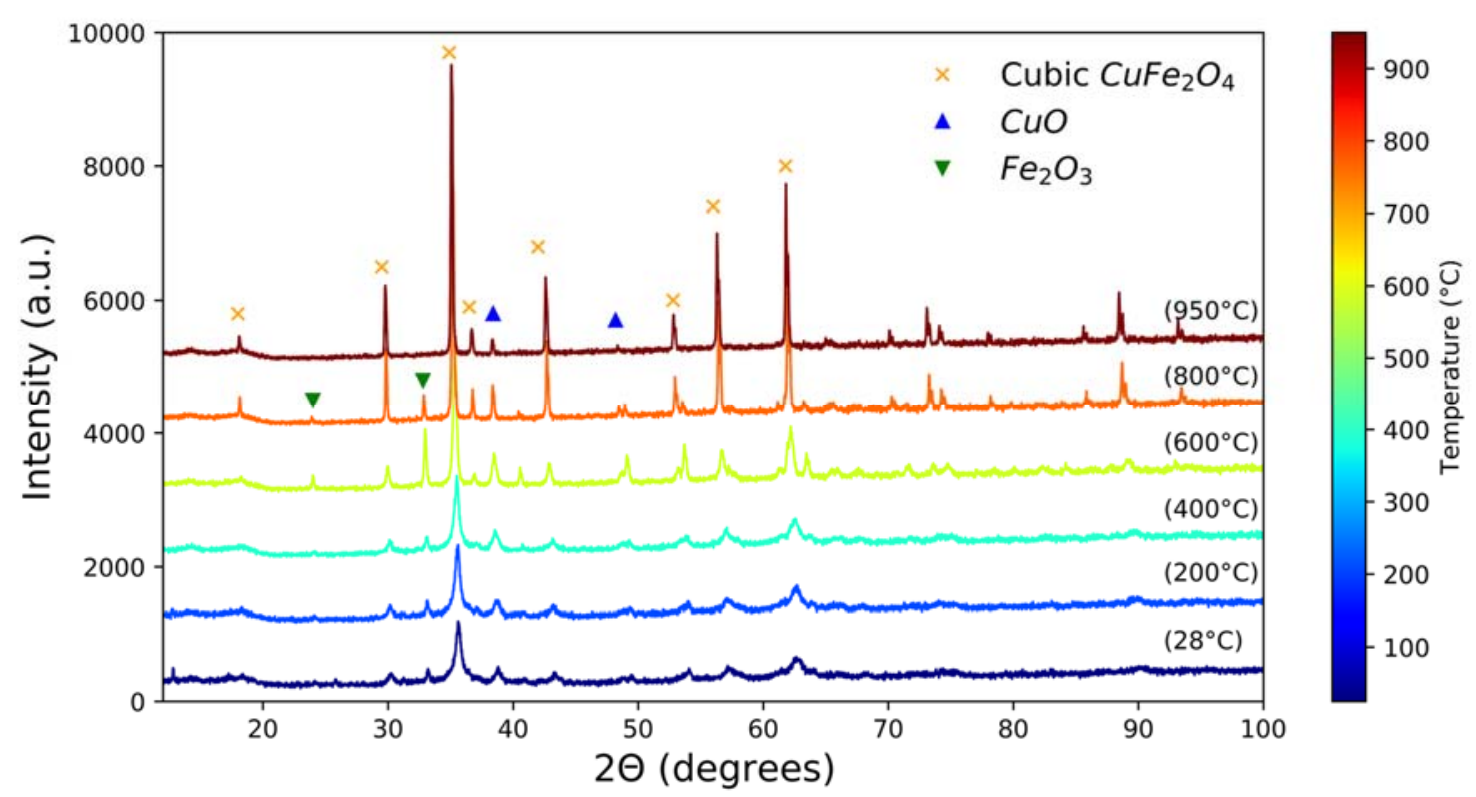

Figure 4. Temperature dependent XRD patterns obtained during the heating process of one sample prepared by the sol-gel method. Only some patterns are represented, and they have been intentionally displaced 1000 units in order to facilitate their comparison. The different markers indicate the $2 \theta$ positions of the main peaks of the present crystalline phases.

243 First, it is possible to observe that the sample obtained after the gel burning process $\left(28^{\circ} \mathrm{C}\right)$ has a 244 low degree of crystallinity and shows a cubic structure, in good agreement with the results obtained by Zhuravlev et al. ${ }^{34}$ and Khemthong et al. ${ }^{35}$. Moreover, smaller quantities of monoclinic $\mathrm{CuO}$ and rhombohedral $\mathrm{Fe}_{2} \mathrm{O}_{3}$ are also present. The low crystallinity degree remains until $600{ }^{\circ} \mathrm{C}$, where the background decreases and the intensity of all phases abruptly increase. Above this temperature, the chemical reaction starts as the cubic $\mathrm{CuFe}_{2} \mathrm{O}_{4}$ peaks grow while those corresponding to former oxides reduce until reaching the maximum temperature. At this point, some small quantities of $\mathrm{CuO}$ are still present, as it commonly happens in high-temperature methods ${ }^{39}$. In order to get more precise information about this process, Figure 5 provides magnified images of the different characteristic peaks for all the measured temperatures. 

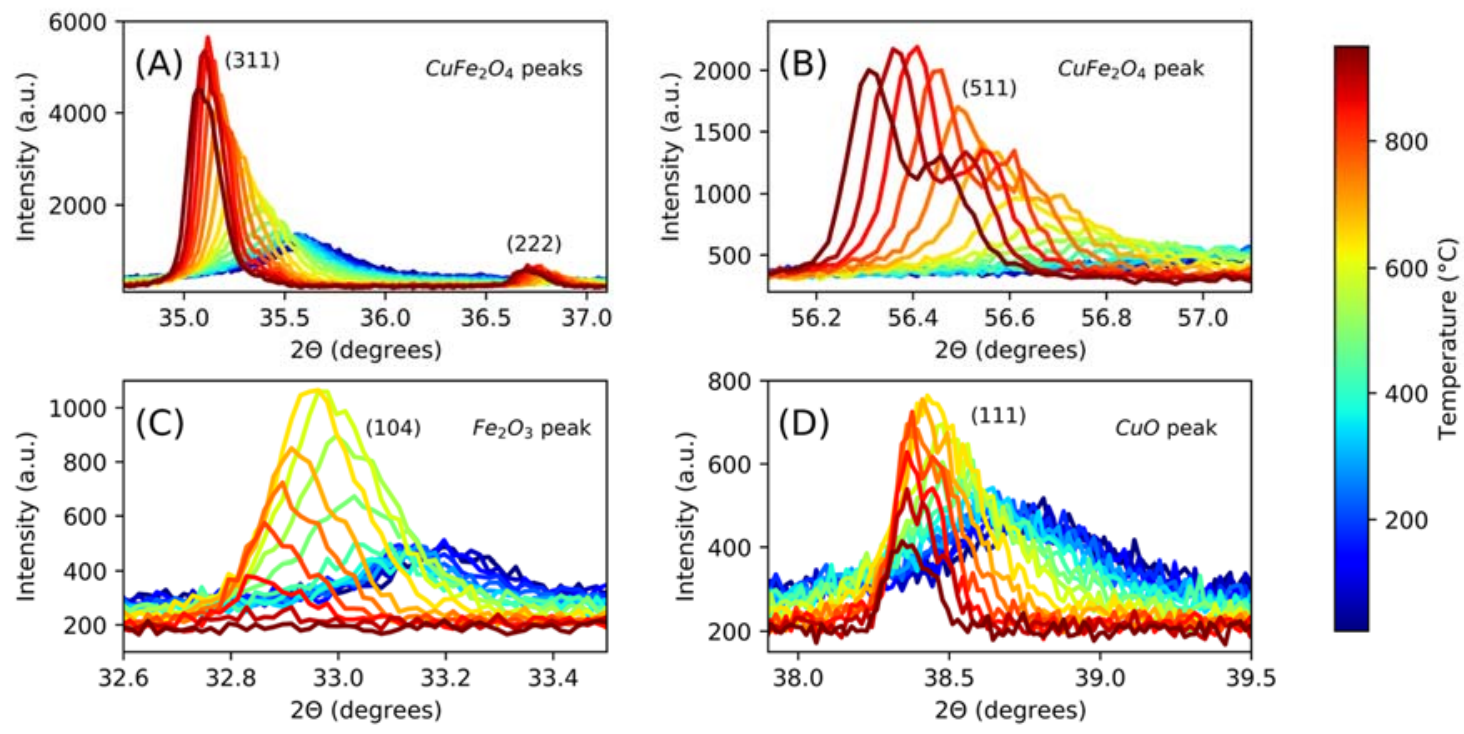

254

Figure 5. Zoomed regions of the temperature dependent XRD measurements for the sol-gel sample during the heating process. (A) and (B) contain the (311), (222) and (511) cubic $\mathrm{CuFe}_{2} \mathrm{O}_{4}$ peaks, (C) contains the (104) $\mathrm{Fe}_{2} \mathrm{O}_{3}$ peak, and (D) the (111) $\mathrm{CuO}$ peak.

It is possible to see, in Figure 5.A, that the (311) peak remains almost invariable until $500{ }^{\circ} \mathrm{C}$, but then starts to increase and shifts to lower $2 \theta$ positions. This displacement is due to an increase of the unit cell parameters at high temperatures. Moreover, an additional low-intensity (222) peak appears at around $36.6^{\circ}$. The same happens in Figure 5.B, although in this case the doublet corresponding to the $\mathrm{K}_{\alpha 1}$ and $\mathrm{K}_{\alpha 2}$ is better defined.

Figure 5.C represents the behaviour of the rhombohedral $\mathrm{Fe}_{2} \mathrm{O}_{3}$ phase. It is evident how the (104) peak intensity grows from $500{ }^{\circ} \mathrm{C}$ until reaching a maximum at $650{ }^{\circ} \mathrm{C}$ due to an improvement of the crystallinity. Then, it decreases - due to the start of the chemical reaction to form the ferrite until completely disappearing at $900{ }^{\circ} \mathrm{C}$. $\mathrm{CuO}$ has a similar behaviour: as it is appreciated in Figure 5.D, the resolution of the (111) peak improves above $\sim 500^{\circ} \mathrm{C}$, and also starts to reduce at $650{ }^{\circ} \mathrm{C}$. The main difference is that, in the case of $\mathrm{CuO}$, it is not completely consumed and there is some remaining intensity at $950{ }^{\circ} \mathrm{C}$.

The cubic phase is the dominant phase at high temperatures, as could be expected from literature. However, the tetragonal phase is formed when cooling the sample back to room temperature, as it can be appreciated in Figure 6.
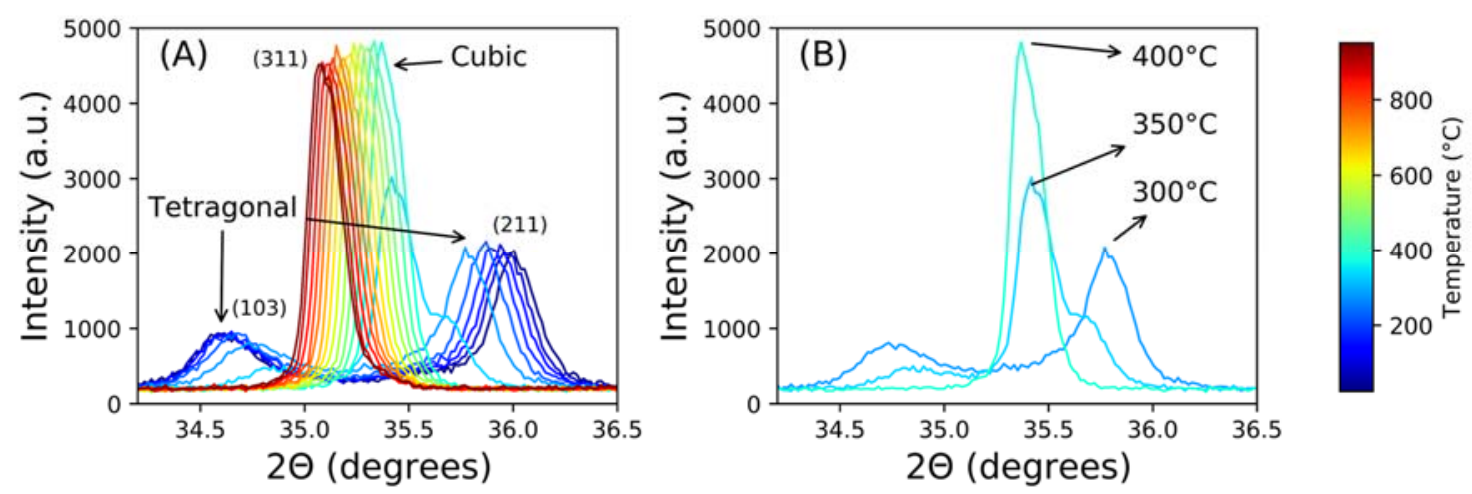

Figure 6. (311) cubic, and (103) and (211) tetragonal $\mathrm{CuFe}_{2} \mathrm{O}_{4}$ reflections of the temperature dependent XRD measurements for the sol-gel sample during the cooling process. In (A) all the performed measurements are shown, while, in (B) only those patterns close to the cubic-to-tetragonal transition are plotted. 
During the cooling process the cubic (311) peak shifts to higher $2 \theta$ positions due to the cell contraction. However, at approximately $350{ }^{\circ} \mathrm{C}$ the cubic peak suddenly reduces, and a doublet appears, which corresponds to the tetragonal phase. The transformation is complete at $300{ }^{\circ} \mathrm{C}$. This transformation temperature range is close to the one expected for the cubic-to-tetragonal transition according to the previously mentioned references.

The same experience, with the identical heating and cooling rates has been performed with a powder samples obtained by co-precipitation.

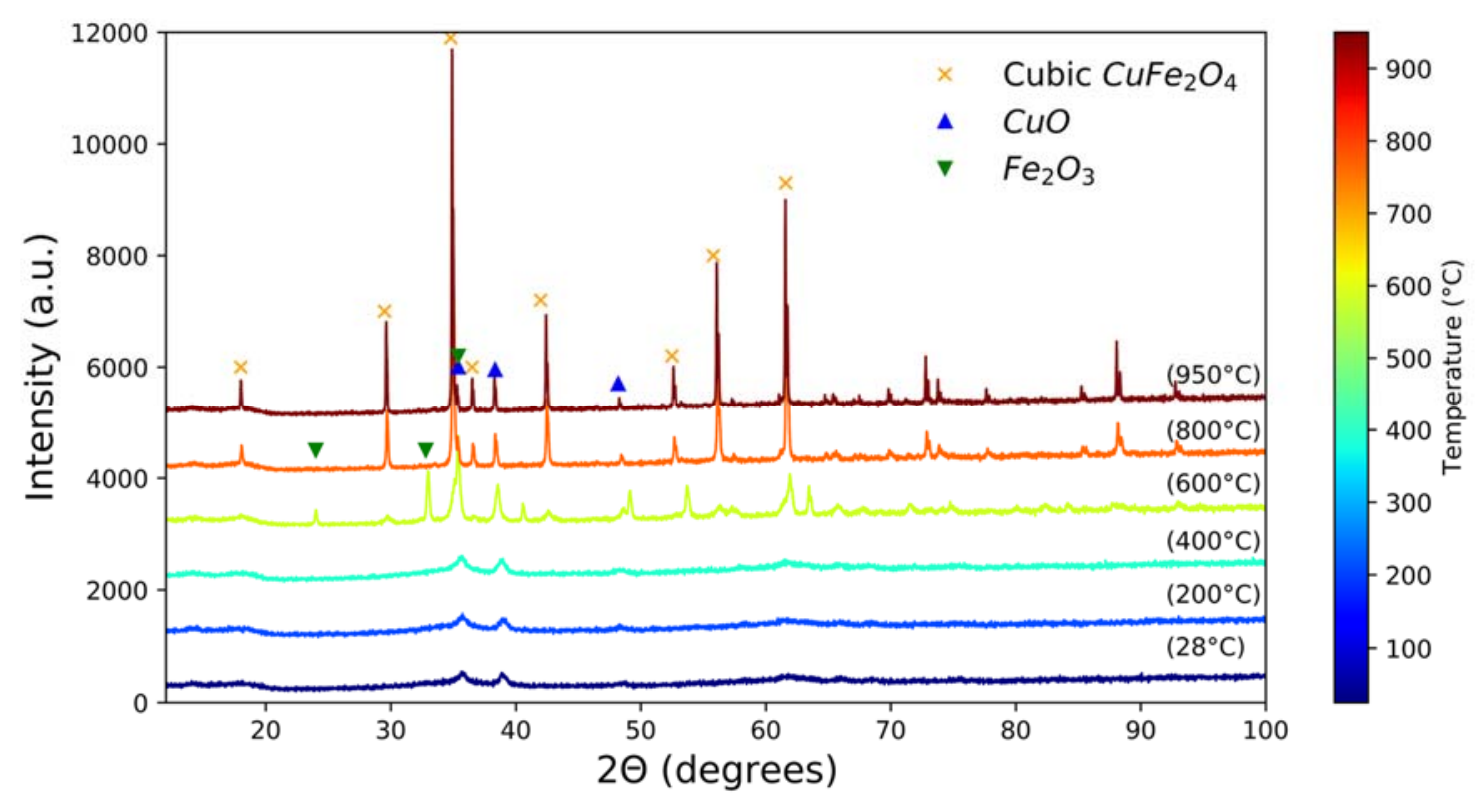

Figure 7. Temperature dependent XRD patterns obtained during the heating process of one sample prepared by the coprecipitation method. Only some patterns are represented, and they have been intentionally displaced 1000 units in order to facilitate their comparison. The different markers indicate the $2 \theta$ positions of the main peaks of the present crystalline phases.

288 In this case, it is observed a poor crystalline structure until $600{ }^{\circ} \mathrm{C}$. The two peaks which are detected in the low-temperature region correspond to $\mathrm{CuO}$ and $\mathrm{Fe}_{2} \mathrm{O}_{3}$, indicating that the chemical reaction has not yet started. The cubic phase starts to form at $600{ }^{\circ} \mathrm{C}$ and is completely formed at $800{ }^{\circ} \mathrm{C}$, when the peaks corresponding to the former oxides are almost null. Furthermore, as it did happen in the previous case, there is some $\mathrm{CuO}$ remaining at $950{ }^{\circ} \mathrm{C}$. In order to have more specific information about the cubic ferrite formation, Figure 8 shows some characteristic peaks at higher magnifications at all the measured temperatures. 

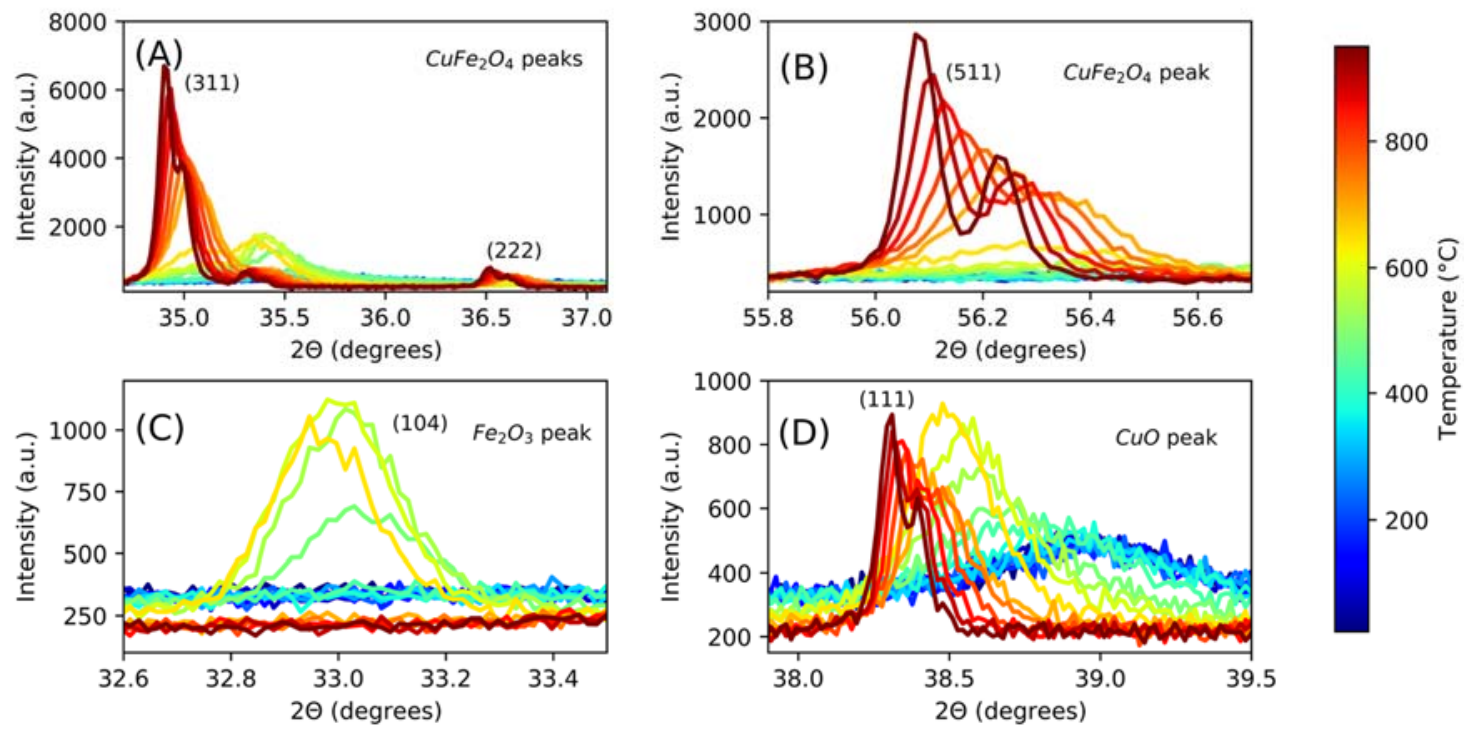

Figure 8. Zoomed regions of the temperature dependent XRD measurements for the sol-gel sample during the heating process. (A) and (B) contain the (311), (222) and (511) cubic $\mathrm{CuFe}_{2} \mathrm{O}_{4}$ peaks, (C) contains the (104) $\mathrm{Fe}_{2} \mathrm{O}_{3}$ peak, and (D) the (111) $\mathrm{CuO}$ peak.

In Figure 8.A and Figure 8.B it is possible to see that the cubic ferrite is not present before starting the annealing process, and starts to be formed between $600{ }^{\circ} \mathrm{C}$ and $650{ }^{\circ} \mathrm{C}$. This threshold temperature defining the start of the cubic phase formation is in agreement with the one previously observed with the sol-gel samples. In addition, the crystalline transition and ferrite formation can be clearly detected in this figure. The $\mathrm{Fe}_{2} \mathrm{O}_{3}$ peak (Figure 8.C) remains shielded by the background at low temperatures, but it suddenly appears at $500^{\circ} \mathrm{C}$ when the crystallinity improves. Then, it starts to reduce its intensity at $650^{\circ} \mathrm{C}$ and is completely consumed at $800{ }^{\circ} \mathrm{C}$. CuO follows the same tendency except for the fact that it is not completely consumed, and the peak intensity is still detected at $950{ }^{\circ} \mathrm{C}$. The crystalline transition and ferrite formation temperatures observed in Figure 8.D are in good agreement with those observed for the other two phases.

The cubic phase is stable at high temperatures, as could be expected. However, there is a main difference compared with the sol-gel sample: here the cubic phase is continuously formed during the heating process, while in the sol-gel case it was previously formed when burning the gel.

As has been seen with the standard XRD measurements presented in Figure 1, co-precipitation method leads to the cubic phase at room temperature. Therefore, the high-temperature structure remains stable when cooling back down, as can be appreciated in Figure 9. There, it can be seen how the only variation is that the (311) peak shifts to higher $2 \theta$ positions due to a reduction of cell parameter during contraction. 


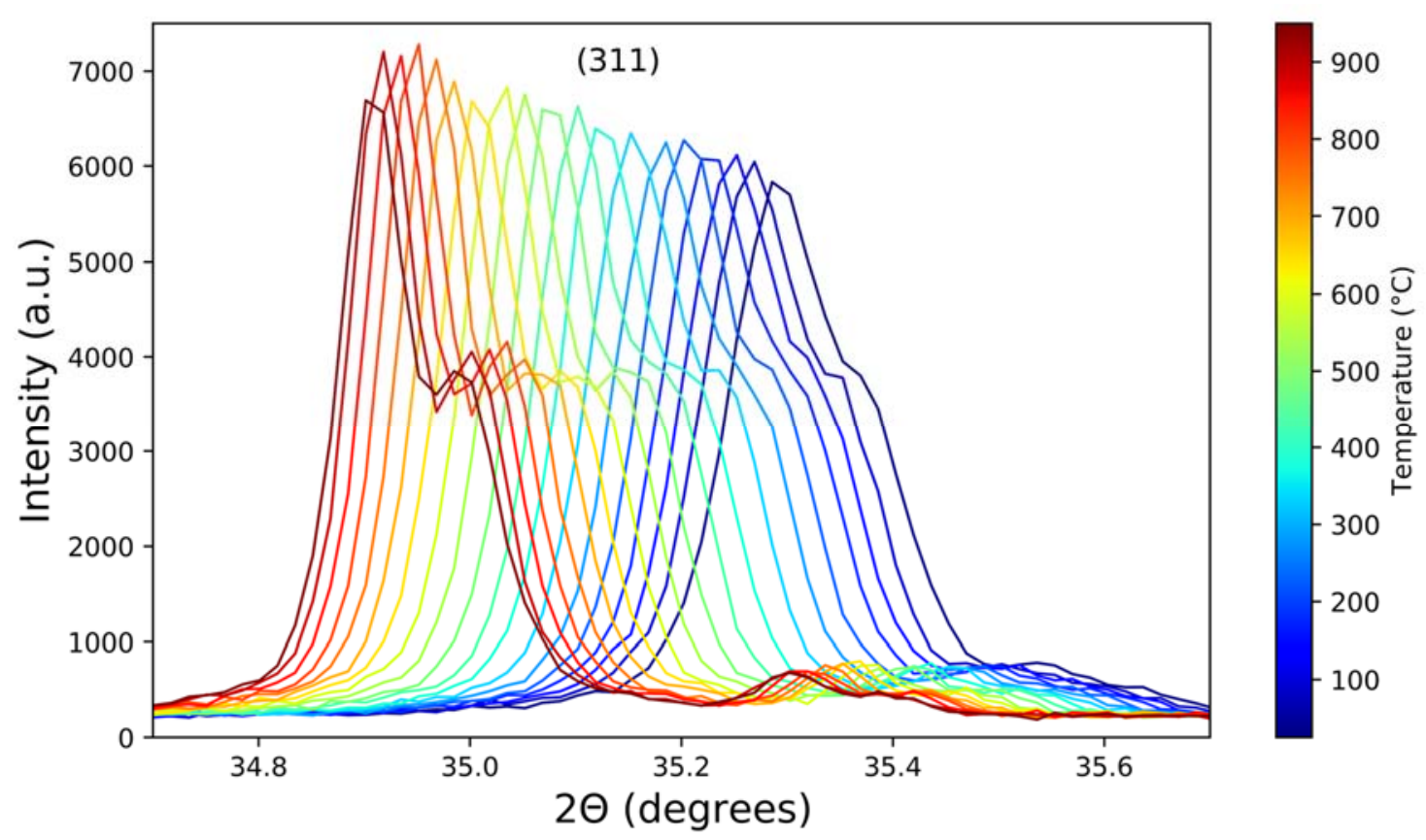

Figure 9. (311) $\mathrm{CuFe}_{2} \mathrm{O}_{4}$ peak of the temperature dependent XRD measurements for the co-precipitation sample during the cooling process.

320 Finally, Figure 10 provides a more general comparison of the peaks corresponding to the different phases at different moments of the annealing process. The existence of cubic $\mathrm{CuFe}_{2} \mathrm{O}_{4}$ before the annealing process is evident in this image, while it is completely inexistent for the co-precipitation process. However, an important fact that can be noticed from this figure is the difference in the cubic $\mathrm{CuFe}_{2} \mathrm{O}_{4}$ peak at $950{ }^{\circ} \mathrm{C}$. The cubic (311) peak in the sol-gel sample is slightly above $35.0^{\circ}$, while it is below this value in the co-precipitation sample. This difference in the peak position indicates a different unit cell parameter in each sample. Consequently, the cubic phase produced by each method at $950{ }^{\circ} \mathrm{C}$ seems to have meaningful structural differences. This is an important observation as it may explain the stability of the cubic and tetragonal phase when cooling down for each method. 

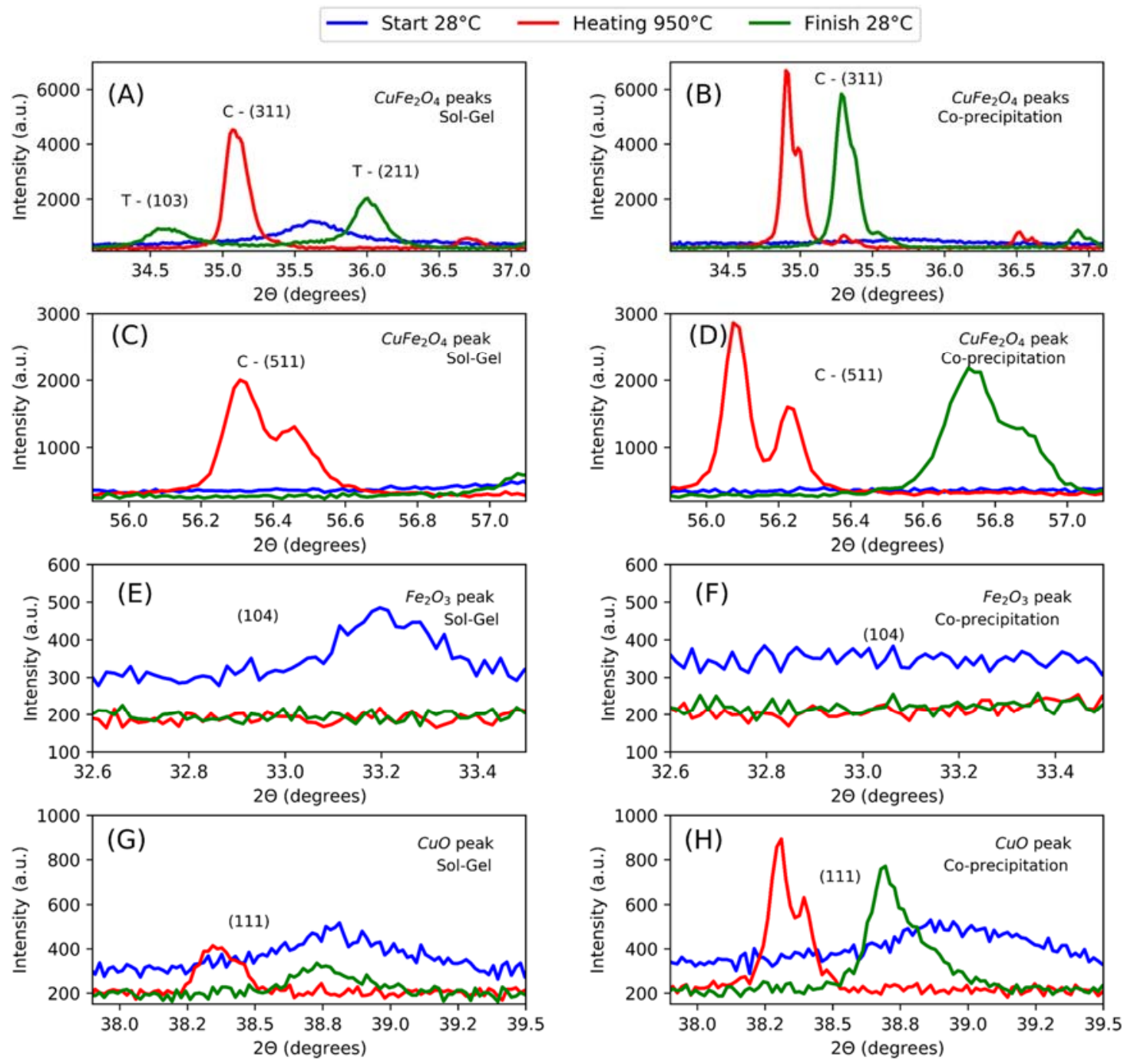

Figure 10. Comparison of the main peaks of each phase, for both samples during the heating and cooling process. The figures in the left column correspond to the samples prepared by sol-gel, while the right column shows the patterns of the co-precipitation samples. (A) and (B) correspond to the cubic (311) and tetragonal (103) and (211) $\mathrm{CuFe}_{2} \mathrm{O}_{4}$ reflections, (C) and (D) correspond to the cubic (511) $\mathrm{CuFe}_{2} \mathrm{O}_{4}$ reflection, (E) and (F) correspond to the (104) $\mathrm{Fe}_{2} \mathrm{O}_{3}$ reflection, and $(\mathrm{G})$ and $(\mathrm{H})$ correspond to the (111) $\mathrm{CuO}$ reflection.

Although previous works justified the formation of each phase by means of the cooling rates in the annealing process or the atmospheric conditions, our results demonstrate the formation of the two different crystal structures under the same annealing conditions. The explanation of why the cubic phase produced by co-precipitation is stable when cooling down the sample, but not the one prepared by sol-gel is not a straightforward task. In contrast to previous publications, our results suggest that the stability of one phase or the other is more related to the history of the sample than to the annealing cooling rate. The evidenced structural differences in the cubic phase at $950{ }^{\circ} \mathrm{C}$ between each method, as well as the formation of a premature cubic phase in the gel burning process, suggest that the sol-gel method forms a metastable cubic phase that is unstable when cooling down to room temperature after annealing. On the other hand, the cubic phase continuously formed by the co-precipitation method is able to be arranged in a such stable configuration that remains when the sample is cooled down. Considering that high temperature treatments lead to structural and magnetic disorders and that a deficit of $\mathrm{Cu}^{2+}$ in the $\mathrm{S}_{\mathrm{T}}$ has been reported for the room-temperature cubic phase ${ }^{40}$, it can be understood that the gel burning process leads to a different cation distribution (i.e. inversion parameter) compared with the continuous ferrite formation during the co-precipitation annealing. This different cation distribution, 
especially in the case of the $\mathrm{Cu}^{2+}$ ion, has a direct influence on reducing the crystal symmetry by the Jahn-Teller effect. Therefore, a difference on the system energy due to the different cations distribution may explain the difference in stability between the two cubic phases when cooling down. A deeper crystallographic analysis of these parameters could confirm this hypothesis.

In a recent paper, Nikolic et al. ${ }^{41}$ proved that an increase on the Fe content favours the cubic phase stabilization. They provide a deep discussion about the $\mathrm{Fe}^{3+}$ incorporation on the $\mathrm{CuO}^{42}$ structure through the $\mathrm{Cu}^{2+}$ release to form the $\mathrm{CuFe}_{2} \mathrm{O}_{4}$. Therefore, the oxygen release during the cooling process affects to the cubic or tetragonal stabilization. These conclusions agree with our explanation. Although all of our samples have been prepared with the same $\mathrm{Fe}^{3+} / \mathrm{Cu}^{2+}$ ratio (contrary to the experimental procedure presented in ${ }^{41}$ ), it is the gel burning process the one that quenches a premature cubic phase with a non-equilibrium cation distribution. This is then the key point, as it affects to the $\mathrm{Cu}^{2+}$ sides occupancy (i.e. to the Jahn-Teller effect) and to the Fe content on the $\mathrm{CuFe}_{2} \mathrm{O}_{4}$ structure. Furthermore, notice that the $\mathrm{CuO}$ content (Table 1) is larger for the coprecipitation samples than for the sol-gel ones (i.e. a larger Fe content for co-precipitation samples), in good agreement with this argumentation.

The effect of the synthesis method on the particle size distribution is analysed by LD measurements. Figure 11 shows the results for each sample.
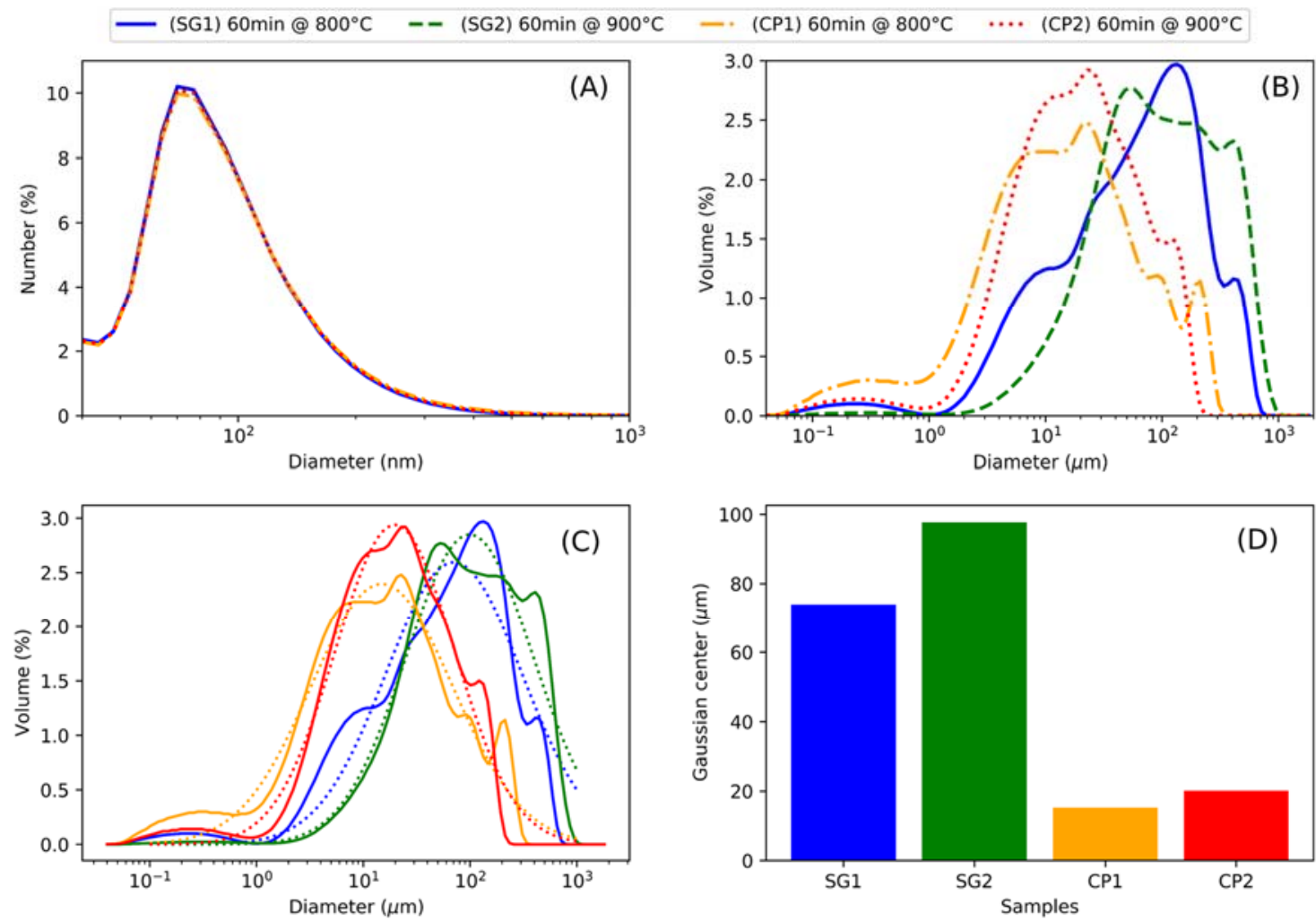

Figure 11. Particle size distribution of the four samples: (A) represented as a function of the percentage of particles, and (B) as the percentage of volume that each diameter represents in the whole sample. (C) shows the fitting between the gaussian and the experimental distributions, while (D) summarizes the mean size values obtained from the gaussian fitting.

In both cases the number \% distribution is under $100 \mathrm{~nm}$, meaning that most of the synthesized particles can be considered as nanoparticles. The small difference that can be found between curves in Figure 11.A is not significant because the device resolution in this range is not sufficient. The average particle size is of $94.0 \pm 0.8 \mathrm{~nm}$. On the other hand, Figure 11.B shows the percentage of the volume of the sample that is occupied for each particle size. There, the first remarkable aspect is the difference in particle size between those samples prepared by sol-gel and those 
prepared by co-precipitation: smaller sizes are achieved by the co-precipitation method, with a difference of one order of magnitude when comparing the centre of their distributions. Moreover, by comparing the two samples prepared by the same approach, it is possible to see how the distributions are displaced to larger diameters in those specimens treated at higher temperatures, especially in the sol-gel case. In order to extract quantitative information about the volume \% distributions, a gaussian distribution has been fitted to the experimental data (see Figure 11.C). The mean particle size for each distribution (which are represented in Figure 11.D) clearly show, following the trend previously commented, the dependence of the particle size with the synthesis method and annealing temperature. These results are coherent with what could be expected from a particle growth point of view.

There is another remarkable aspect in the volume \% distribution: the existence of a smaller population with some hundreds of nanometres in diameter. Considering that each order of magnitude in diameter has $10^{3}$ times less influence in the volume contribution, this population is of immense importance and possibly corresponds to the nanometric population detected in Figure 11.A.

As it can be observed, the volumetric distributions shown in Figure 11.C are not regular and are formed by the superposition of multiple distributions. We have used the Ulm and Constantinides method ${ }^{43-46}$ to deconvolute the individual gaussian distributions that lead to the general profile. The deconvolution for each of the four samples is shown in Figure 12. In addition, a summary of the obtained data is provided in Table 3.
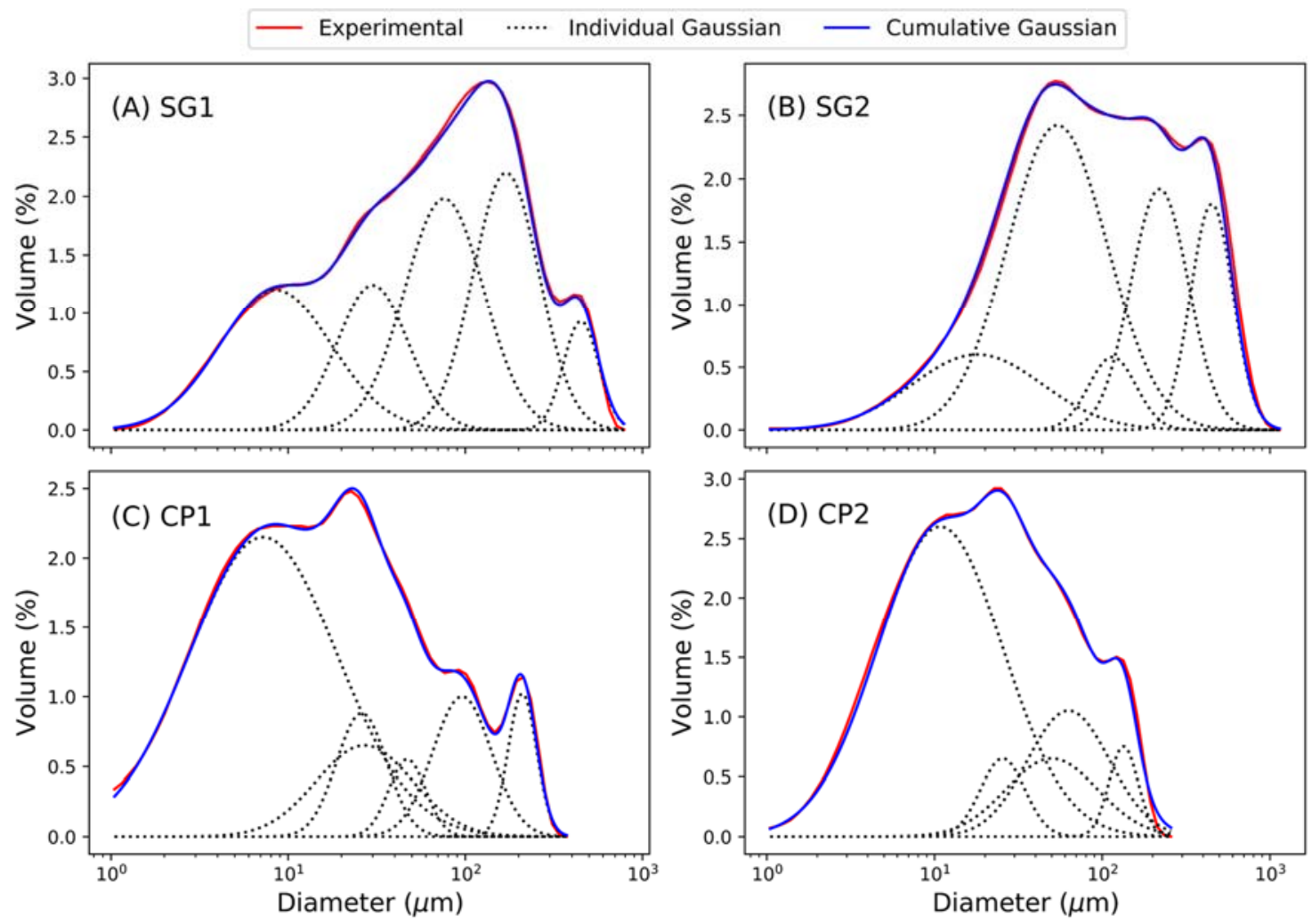

Figure 12. Deconvolution of the volumetric particle size distributions of the (A) SG1, (B) SG2, (C) CP1, and (D) CP2 
Table 3. Parameters obtained from the deconvolution of the volumetric particle size distributions.

\begin{tabular}{ccc|ccc} 
Sample & $\begin{array}{c}\text { Mean size } \\
(\boldsymbol{\mu m})\end{array}$ & $\begin{array}{c}\text { Relative } \\
\text { area (\%) }\end{array}$ & Sample & $\begin{array}{c}\text { Mean size } \\
(\boldsymbol{\mu m})\end{array}$ & $\begin{array}{c}\text { Relative } \\
\text { area (\%) }\end{array}$ \\
\hline \multirow{4}{*}{ SG1 } & 8.5 & 33.8 & & 18 & 22.2 \\
& 30 & 14.0 & & 54 & 53.7 \\
& 76 & 27.9 & SG2 & 115 & 2.8 \\
& 170 & 21.7 & & 220 & 14.2 \\
& 450 & 2.6 & & 450 & 7.1 \\
\hline \multirow{4}{*}{ CP1 } & 7.2 & 77.9 & & 10.8 & 73.9 \\
& 26 & 3.7 & & 25.5 & 2.3 \\
& 27 & 10.0 & \multirow{2}{*}{ CP2 } & 50 & 9.9 \\
& 47 & 1.3 & & 63 & 12.8 \\
& 96 & 5.7 & & 134 & 1.1 \\
& 210 & 1.4 & & &
\end{tabular}

409 The first aspect that can be observed for the sol-gel samples is that the smaller distribution is 410 centred at $\sim 8.5 \mu \mathrm{m}$ and $\sim 18 \mu \mathrm{m}$ for the samples prepared at $800{ }^{\circ} \mathrm{C}$ and $900{ }^{\circ} \mathrm{C}$, respectively. 411 Furthermore, this is the most popular distribution for the SG1 sample, while it moves to $54 \mu \mathrm{m}$ 412 for SG2. These two observations agree with the general tendency observed in Figure 11 and with 413 what could be thermodynamically expected. In addition, the distribution is wider for the sample 414 annealed at $800{ }^{\circ} \mathrm{C}$ than the one at $900{ }^{\circ} \mathrm{C}$. On the other hand, the samples prepared by co415 precipitation mainly consist on one major distribution on the low-size range, and a set of 416 complementary smaller distributions with larger diameters. Again, we see that the main distribution for the sample prepared at $800{ }^{\circ} \mathrm{C}$ is smaller than the one for the sample prepared at $418900{ }^{\circ} \mathrm{C}$. Finally, the main distribution values are smaller for the co-precipitation samples than for 419 the sol-gel ones.

420 SEM images shown in Figure 13 complements the size study of these particles and give information about their shape and distribution. 

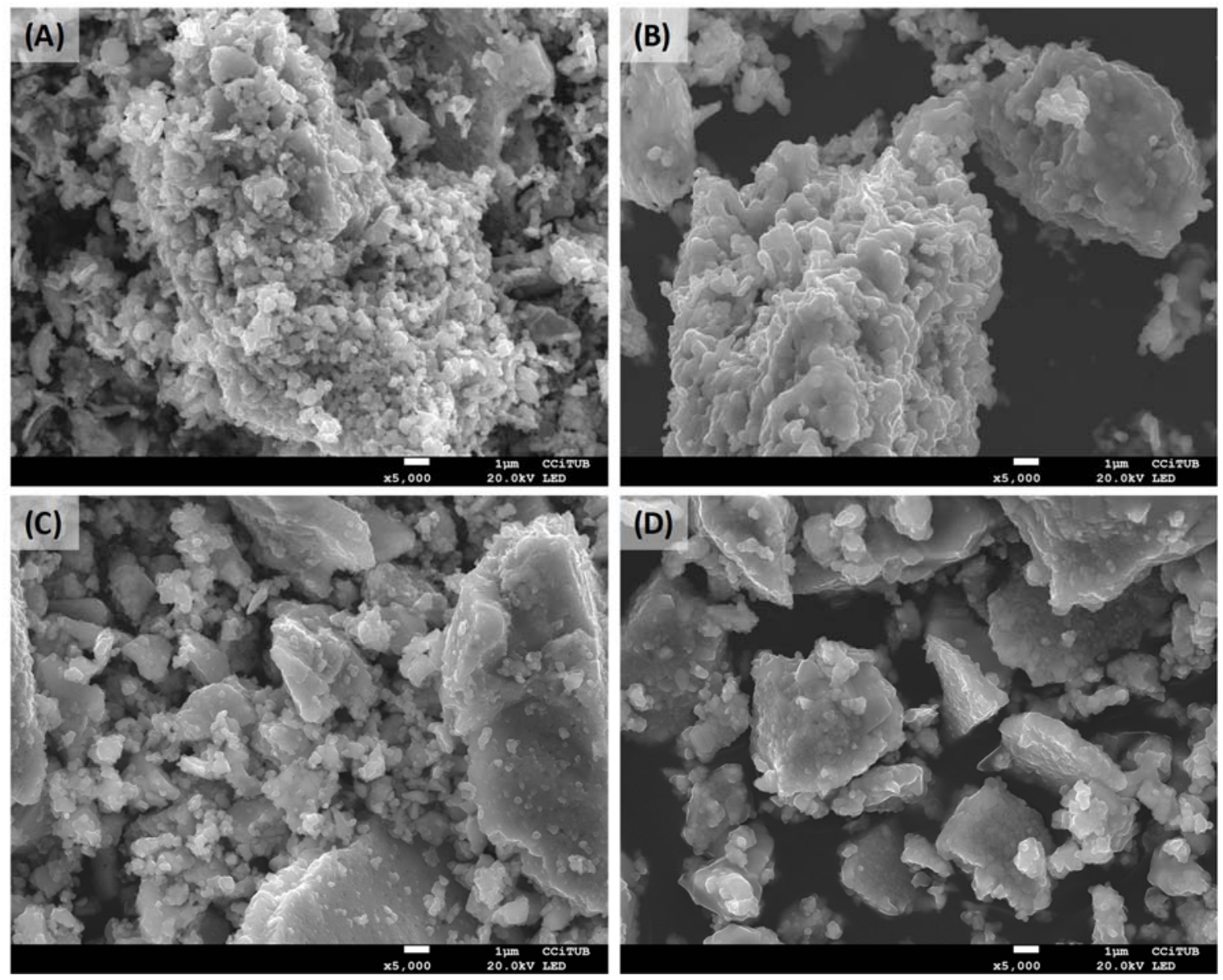

Figure 13. SEM images at $x 5000$ magnification of (A) SG1, (B) SG2, (C) CP1, and (D) CP2 samples.

In all cases, it is possible to see how a large number of small particles aggregate forming micrometic clusters. The diameter of the smaller fraction is similar in all samples and they are under one micron in size. On the other hand, the aggregates are of some tens of microns in diameter and they are qualitatively bigger for sol-gel samples than for co-precipitation ones. All of these conclusions are in agreement with the results obtained by LD measurements. Furthermore, it is worth to notice that nanometric particles are almost spherical shaped, whereas the aggregates present random shapes. These random shapes can be one of the reasons why in Figure 11.B the curves are formed by the superposition of multiple distributions: LD assumes spherical particles, so the diffraction with non-uniform particles can generate the effect of having multiple distributions. Moreover, the different sintering between nanoparticles also leads to the formation of micrometric clusters of different sizes. The scale of the aggregates' diameters observed in these images agrees with the quantitative approximations shown in Figure 11.D.

Additionally, when looking at higher magnification (Figure 14) it is seen that there is a direct bonding between particles, i.e. sintering has occurred during thermal processes. This effect has been previously reported in other works ${ }^{20,34,47,48}$ which synthesize the same kind of materials by the same methods. Thus, the nanometric distribution shown in Figure 11.A may represent the individual small population, meanwhile the micrometric one in Figure 11.B may be representative of the aggregates. 


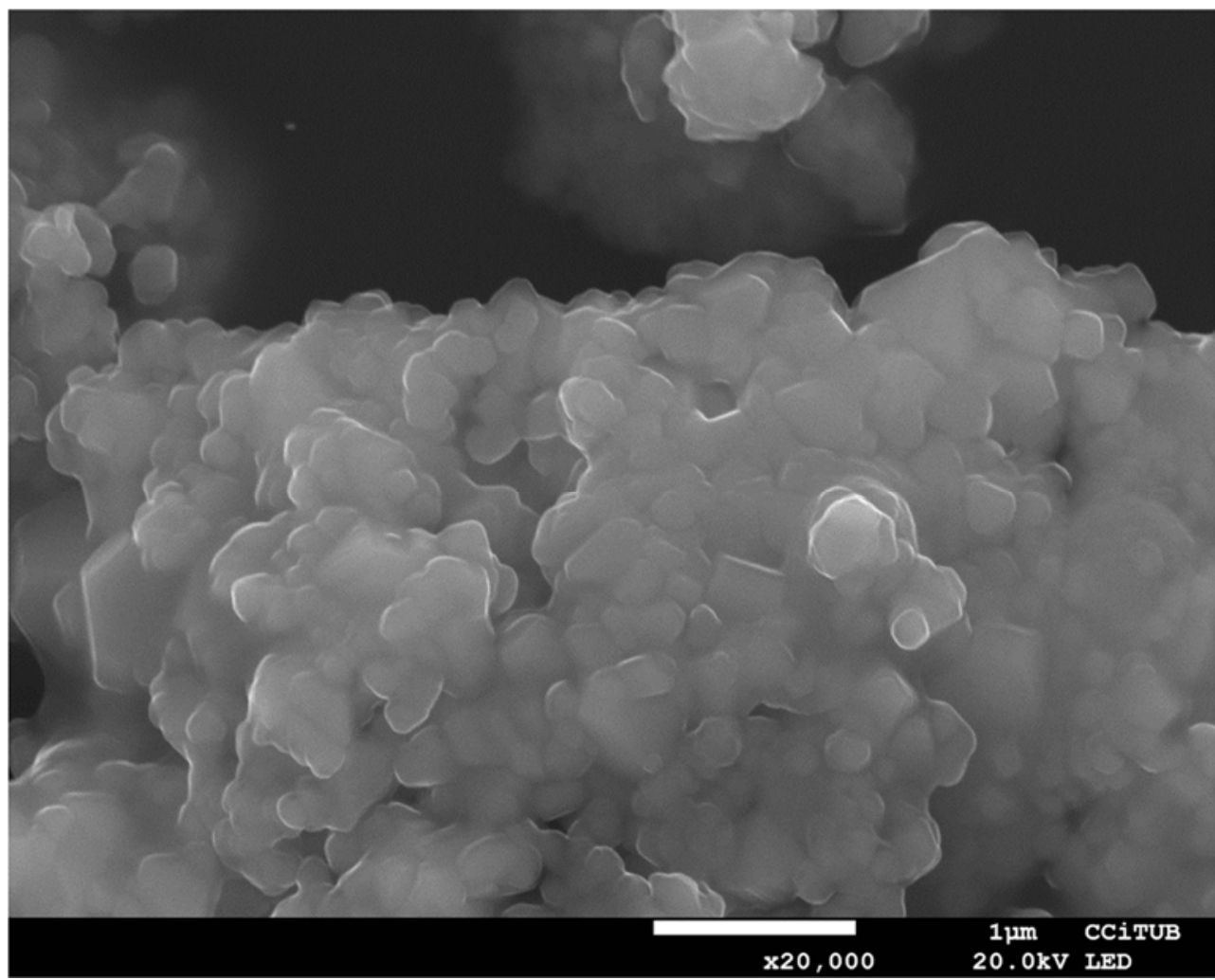

Figure 14. SEM image of sample CP2 at x20000 magnification.

444 Finally, the magnetic properties of all these samples have been measured with a SQUID 445 magnetometer. The hysteresis cycle, $\mathrm{M}(\mathrm{H})$, has been measured at $300 \mathrm{~K}$. Notice that only the first 446 magnetization curve and the demagnetization from the positive to the negative saturations are 447 shown in Figure 15, as the hysteresis has a symmetric behaviour. 


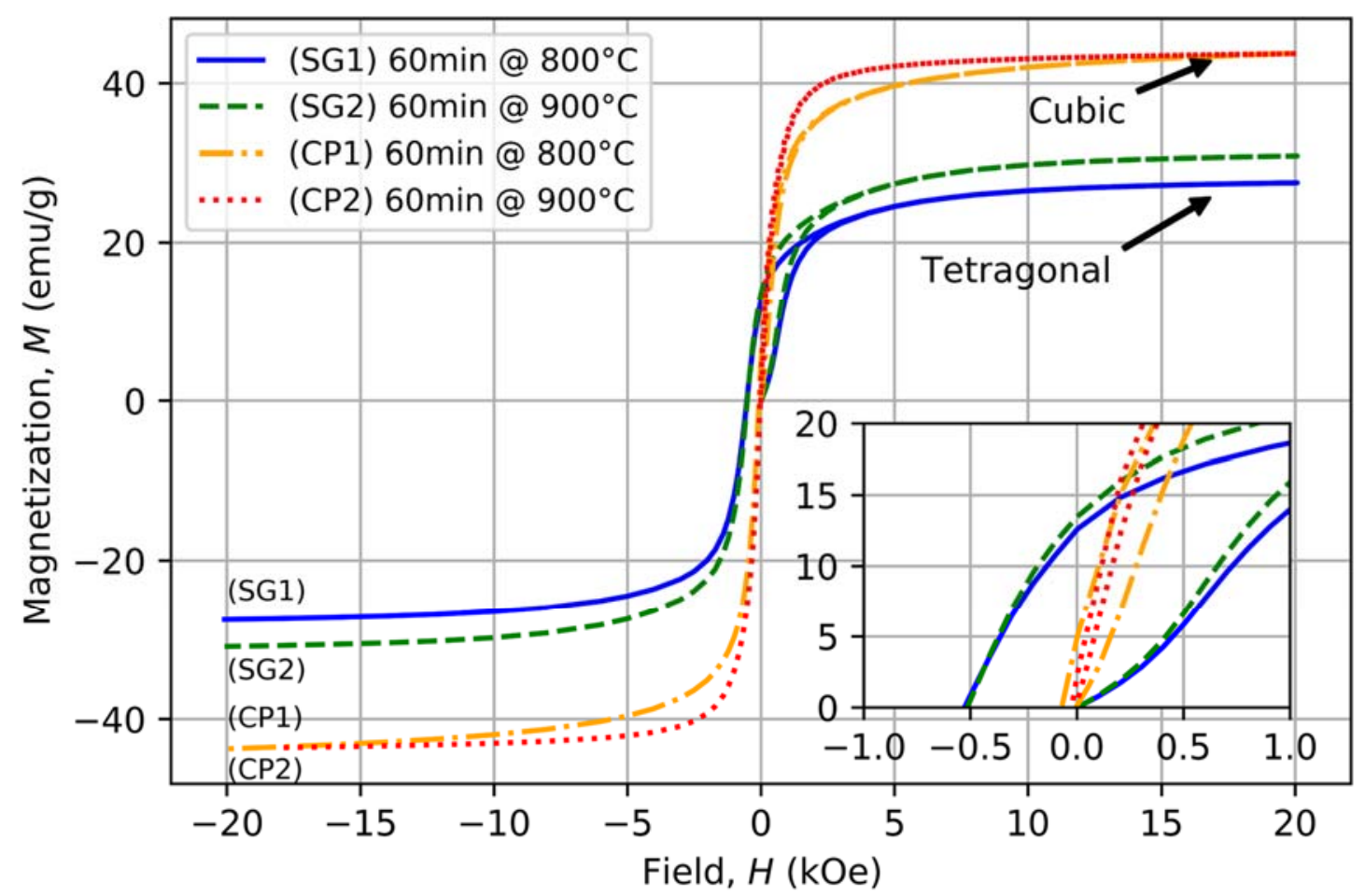

Figure 15. Hysteresis cycle at $300 \mathrm{~K}$ of all the prepared samples. Inner plot is a zoom of the area close to the zero field.

It is clear, from Figure 15, that the materials prepared by each chemical method (i.e. each crystal structure) have a different magnetic behaviour. First, the saturation magnetization $\left(\mathrm{M}_{\mathrm{S}}\right)$ is greater in cubic samples compared with the tetragonal ones. This behaviour is in good agreement with previous works ${ }^{22,49}$ which state that this higher saturation magnetization of the cubic phase compared to the tetragonal one is an indication of the migration of $\mathrm{Cu}^{2+}$ ions to $\mathrm{S}_{\mathrm{T}}$ during the symmetry distortion. As $\mathrm{CuFe}_{2} \mathrm{O}_{4}$ magnetization follows the Néel model, an increased presence of $\mathrm{Cu}^{2+}$ in $\mathrm{S}_{\mathrm{T}}$ leads to an increase in magnetization ${ }^{33}$. The obtained values are considerably larger than those reported for $\mathrm{CuFe}_{2} \mathrm{O}_{4}$ prepared by similar methods ${ }^{20,33,50}$, especially in the case of the cubic structure. The hysteresis amplitude, which is directly related to the energy needed for sweeping the magnetic moment between both states, is also completely different between structures. In this regard, cubic samples present a softer behaviour compared with the tetragonal ones because of their lower remnant magnetization $\left(\mathrm{M}_{\mathrm{R}}\right)$ and coercive field $\left(\mathrm{H}_{\mathrm{C}}\right)$. In Table 4 , the specific values for each property are specified.

Table 4. Magnetic properties of the four prepared samples.

\begin{tabular}{cccc} 
Sample (\#) & $\mathbf{M}_{\mathbf{S}}(\mathbf{e m u} / \mathbf{g})$ & $\mathbf{M}_{\mathbf{R}}(\mathbf{e m u} / \mathbf{g})$ & $\left.\left|\mathbf{H}_{\mathbf{C}}\right| \mathbf{( O e}\right)$ \\
\hline SG1 & 27.4 & 12.6 & 526.6 \\
SG2 & 30.8 & 13.9 & 513.6 \\
CP1 & 43.5 & 4.8 & 70.8 \\
CP2 & 43.6 & 2.1 & 24.4
\end{tabular}


$\mathrm{CuFe}_{2} \mathrm{O}_{4}$ nanoparticles have been successfully synthetized by two different wet chemical methods: sol-gel and co-precipitation. The experimental process has been described in detail in both cases.

Although the reactants and synthesis conditions used in both methods are the same, sol-gel approach produces tetragonal $\mathrm{CuFe}_{2} \mathrm{O}_{4}$ meanwhile co-precipitation forms the cubic form of the same material. This is a key conclusion as the existing literature justifies that the formation of one or the other structure is due to a difference on the experimental thermal conditions. Traces of $\mathrm{CuO}$ are still present in all the samples (especially in those prepared by co-precipitation) meanwhile $\mathrm{Fe}_{2} \mathrm{O}_{3}$ is only present in the sol-gel sample prepared at $800^{\circ} \mathrm{C}$. The XRD profile fitting by Rietveld refinement reveals that the purity of $\mathrm{CuFe}_{2} \mathrm{O}_{4}$ increases with temperature for both methods. Purities up to a $96 \%$ and $88 \%$ are achieved, respectively, by the sol-gel and co-precipitation methods.

The formation and stability of each crystal structure have been observed by means of temperature dependent XRD measurements. From these measurements it has been proved that, in the sol-gel method, the gel burning process produces a metastable cubic $\mathrm{CuFe}_{2} \mathrm{O}_{4}$ phase, which transforms to the tetragonal one after a high-temperature annealing. On the other hand, the co-precipitation cubic phase is continuously formed from $600{ }^{\circ} \mathrm{C}$ and remains stable after the annealing process. The structural differences found between the two cubic structures at $950{ }^{\circ} \mathrm{C}$ may explain their difference in stability. We propose that the initial gel burning process acts as a quenching process that leads to a metastable cubic phase, whose stability is lower when cooling down. According to the Jahn-Taller principles, we believe that this is due to a different cation distribution (i.e. different spinel inversion parameter) that leads to a different system energy. Furthermore, the clear differences in magnetization between both structures supports this idea. However, a more detailed crystallographic study should be done in order to corroborate this hypothesis.

LD particle size analysis has shown that most of the particles have a diameter close to $94 \mathrm{~nm}$, although there are also present micrometre-sized bodies in the samples. SEM microscopy has confirmed the formation of the nanoparticles, and moreover it has proved that the micrometric bodies really consist on sintered nanoparticles. Furthermore, the deconvolution of each of the LD distributions has demonstrated that the size of the sintered bodies clearly depends on the synthesis route and thermal conditions. These results are in excellent agreement with the SEM observations.

The novelty in this work comes from the experimental evidence in the preparation of the tetragonal and cubic $\mathrm{CuFe}_{2} \mathrm{O}_{4}$ structures by two fast and simple techniques by using exactly the same reagents and temperature conditions. Therefore, the capacity for synthetizing $\mathrm{CuFe}_{2} \mathrm{O}_{4}$ via sol-gel or co-precipitation becomes of great importance due to the great technological opportunity it offers to tune the nanoparticles, as the magnetic results show.

\section{AKNOWLEDGEMENTS}

J. Calvo-de la Rosa acknowledges Ajuts a la Docència i a la Recerca (ADR) given by the Universitat de Barcelona and the Catalan Government for the quality accreditation given to his research group DIOPMA (2017 SGR 118). Authors would also like to thank Xavier Alcobé for his collaboration on the XRD measurements and results' interpretation. 
(1) Sumangala, T. P.; Pasquet, I.; Presmanes, L.; Thimont, Y.; Bonningue, C.; Venkataramani, N.; Prasad, S.; Baco-Carles, V.; Tailhades, P.; Barnabé, A. Effect of Synthesis Method and Morphology on the Enhanced CO2 Sensing Properties of Magnesium Ferrite MgFe2O4. Ceram. Int. 2018, 44 (15), 18578-18584. https://doi.org/10.1016/j.ceramint.2018.07.082.

(2) Shekhawat, D.; Roy, P. K. Effect of Cobalt Substitution on Physical \& Electro-Magnetic Properties of SrAl 4 Fe 8 O 19 Hexa-Ferrite. Mater. Chem. Phys. 2019, 229 (July 2017), 183-189. https://doi.org/10.1016/j.matchemphys.2019.03.008.

(3) Kaewmanee, T.; Wannapop, S.; Phuruangrat, A.; Thongtem, T.; Wiranwetchayan, O.; Promnopas, W.; Sansongsiri, S.; Thongtem, S. Effect of Oleic Acid Content on Manganese-Zinc Ferrite Properties. Inorg. Chem. Commun. 2019, 103 (January), 87-92. https://doi.org/10.1016/j.inoche.2019.03.016.

(4) Yang, Y.; Li, J.; Zhao, J.; Chen, X.; Gan, G.; Wang, G.; He, L. Synthesis of Nickel Zinc Ferrite Ceramics on Enhancing Gyromagnetic Properties by a Novel Low-Temperature Sintering Approach for LTCC Applications. J. Alloys Compd. 2019, 778, 8-14. https://doi.org/10.1016/j.jallcom.2018.11.144.

(5) Amiri, S.; Shokrollahi, H. The Role of Cobalt Ferrite Magnetic Nanoparticles in Medical Science. Mater. Sci. Eng. C 2013, 33 (1), 1-8. https://doi.org/10.1016/j.msec.2012.09.003.

(6) Amiri, M.; Salavati-Niasari, M.; Akbari, A. Magnetic Nanocarriers: Evolution of Spinel Ferrites for Medical Applications. Adv. Colloid Interface Sci. 2019, 265, $29-44$. https://doi.org/10.1016/j.cis.2019.01.003.

(7) Kefeni, K. K.; Msagati, T. A. M.; Mamba, B. B. Ferrite Nanoparticles: Synthesis, Characterisation and Applications in Electronic Device. Mater. Sci. Eng. B Solid-State Mater. Adv. Technol. 2017, 215, 37-55. https://doi.org/10.1016/j.mseb.2016.11.002.

(8) Manikandan, V.; Sikarwar, S.; Yadav, B. C.; Mane, R. S. Fabrication of Tin Substituted Nickel Ferrite (Sn-NiFe2O4) Thin Film and Its Application as Opto-Electronic Humidity Sensor. Sensors Actuators, A Phys. 2018, 272, 267-273. https://doi.org/10.1016/j.sna.2018.01.059.

(9) Bashir, B.; Shaheen, W.; Asghar, M.; Warsi, M. F.; Khan, M. A.; Haider, S.; Shakir, I.; Shahid, M. Copper Doped Manganese Ferrites Nanoparticles Anchored on Graphene Nano-Sheets for High Performance Energy Storage Applications. J. Alloys Compd. 2017, 695, 881-887. https://doi.org/10.1016/j.jallcom.2016.10.183.

(10) Chen, T. Y.; Lin, L. Y. Morphology Variation for the Nickel Cobalt Molybdenum Copper Oxide with Different Metal Ratios and Their Application on Energy Storage. Electrochim. Acta 2019, 298, 745-755. https://doi.org/10.1016/j.electacta.2018.12.157.

(11) Kaur, P.; Bahel, S.; Narang, S. B. Broad-Band Microwave Absorption of $\mathrm{Sr} 0.85 \mathrm{La} 0.15(\mathrm{MnZr}) \mathrm{XFe} 12-2 \mathrm{xO} 19$ Hexagonal Ferrite in 18-40 GHz Frequency Range. J. Magn. Magn. Mater. 2018, 460, 489-494. https://doi.org/10.1016/j.jmmm.2018.01.042.

(12) Liu, L.; He, N.; Sun, J.; Hu, P.; He, R.; Cheng, J.; Tian, W.; Tong, G. Tailoring Impedance Match and Enhancing Microwave Absorption of Fe3O4/Bi24Fe2O39/Bi Hollow Porous Microrods by Controlling Their Composition. Prog. Nat. Sci. Mater. Int. 2018, 28 (5), 575-583. https://doi.org/10.1016/j.pnsc.2018.08.008.

(13) Hussain, A.; Bai, G.; Huo, H.; Yi, S.; Wang, X.; Fan, X.; Yan, M. Co2O3 and SnO2 Doped MnZn Ferrites for Applications at 3-5 MHz Frequencies. Ceram. Int. 2019, 45 
(9), 12544-12549. https://doi.org/10.1016/j.ceramint.2019.03.193.

(14) Liu, S.; Wei, K.; Cheng, Y.; Yan, S.; He, L.; Deng, L. Structural, Magnetic and Microwave Electromagnetic Properties in La-Substituted Quaternary Ferrite. J. Alloys Compd. 2019, 791, 469-476. https://doi.org/10.1016/j.jallcom.2019.03.227.

(15) Balagurov, A. M.; Bobrikov, I. A.; Pomjakushin, V. Y.; Sheptyakov, D. V.; Yushankhai, V. Y. Interplay between Structural and Magnetic Phase Transitions in Copper Ferrite Studied with High-Resolution Neutron Diffraction. J. Magn. Magn. Mater. 2015, 374, 591-599. https://doi.org/10.1016/j.jmmm.2014.08.092.

(16) Ata-Allah, S. S.; Hashhash, A. Jahn-Teller Effect and Superparamagnetism in Zn Substituted Copper-Gallate Ferrite. J. Magn. Magn. Mater. 2006, 307 (2), 191-197. https://doi.org/10.1016/j.jmmm.2006.04.002.

(17) Satheeshkumar, M. K.; Ranjith Kumar, E.; Srinivas, C.; Prasad, G.; Meena, S. S.; Pradeep, I.; Suriyanarayanan, N.; Sastry, D. L. Structural and Magnetic Properties of $\mathrm{CuFe} 2 \mathrm{O} 4$ Ferrite Nanoparticles Synthesized by Cow Urine Assisted Combustion Method. J. Magn. Magn. Mater. 2019, 484 (April), 120-125. https://doi.org/10.1016/j.jmmm.2019.03.128.

(18) Abdellatif, M. H.; Innocenti, C.; Liakos, I.; Scarpellini, A.; Marras, S.; Salerno, M. Effect of Jahn-Teller Distortion on the Short Range Magnetic Order in Copper Ferrite. $J$. Magn. Magn. Mater. 2017, 424 (September 2016), 402-409. https://doi.org/10.1016/j.jmmm.2016.10.110.

(19) Caddeo, F.; Loche, D.; Casula, M. F.; Corrias, A. Evidence of a Cubic Iron Sub-Lattice in t-CuFe2O4 Demonstrated by X-Ray Absorption Fine Structure. Sci. Rep. 2018, 8 (1), 1-12. https://doi.org/10.1038/s41598-017-19045-8.

(20) López-Ramón, M. V.; Álvarez, M. A.; Moreno-Castilla, C.; Fontecha-Cámara, M. A.; Yebra-Rodríguez, Á.; Bailón-García, E. Effect of Calcination Temperature of a Copper Ferrite Synthesized by a Sol-Gel Method on Its Structural Characteristics and Performance as Fenton Catalyst to Remove Gallic Acid from Water. J. Colloid Interface Sci. 2018, 511, 193-202. https://doi.org/10.1016/j.jcis.2017.09.117.

(21) Valenzuela, R. Magnetic Ceramics; Cambridge University Press, 1994.

(22) Yokoyama, M.; Nakamura, A.; Sato, T.; Haneda, K. Jahn-Teller Effect in Ultrafine Copper Ferrite Particles. J. Magn. Soc. Japan 1998, 22 (S1), 243-245. https://doi.org/10.3379/jmsjmag.22.s1_243.

(23) Balagurov, A. M.; Bobrikov, I. A.; Maschenko, M. S.; Sangaa, D.; Simkin, V. G. Structural Phase Transition in CuFe2O4 Spinel. Crystallogr. Reports 2013, 58 (5), 710717. https://doi.org/10.1134/S1063774513040044.

(24) Rocha, A. K. S.; Magnago, L. B.; Pegoretti, V. C. B.; de Freitas, M. B. J. G.; Lelis, M. F. F.; Fabris, J. D.; Porto, A. O. Copper Local Structure in Spinel Ferrites Determined by X-Ray Absorption and Mössbauer Spectroscopy and Their Catalytic Performance. Mater. Res. Bull. 2019, 109 (October 2017), 117-123. https://doi.org/10.1016/j.materresbull.2018.09.017.

(25) Ibrahim, E. M. M.; Abdel-Rahman, L. H.; Abu-Dief, A. M.; Elshafaie, A.; Hamdan, S. K.; Ahmed, A. M. The Synthesis of $\mathrm{CuO}$ and NiO Nanoparticles by Facile Thermal Decomposition of Metal-Schiff Base Complexes and an Examination of Their Electric, Thermoelectric and Magnetic Properties. Mater. Res. Bull. 2018, 107 (August), 492-497. https://doi.org/10.1016/j.materresbull.2018.08.020.

(26) Hernández-Hernández, A. A.; Álvarez-Romero, G. A.; Castañeda-Ovando, A.; Mendoza-Tolentino, Y.; Contreras-López, E.; Galán-Vidal, C. A.; Páez-Hernández, M. 
E. Optimization of Microwave-Solvothermal Synthesis of Fe3O4 Nanoparticles. Coating, Modification, and Characterization. Mater. Chem. Phys. 2018, 205, 113-119. https://doi.org/10.1016/j.matchemphys.2017.11.009.

(27) Hu, S. L.; Liu, J.; Yu, H. Y.; Liu, Z. W. Synthesis and Properties of Barium Ferrite Nano-Powders by Chemical Co-Precipitation Method. J. Magn. Magn. Mater. 2019, 473 (August 2018), 79-84. https://doi.org/10.1016/j.jmmm.2018.10.044.

(28) Hutamaningtyas, E.; Utari; Suharyana; Purnama, B.; Wijayanta, A. T. Effects of the Synthesis Temperature on the Crystalline Structure and the Magnetic Properties of Cobalt Ferrite Nanoparticles Prepared via Coprecipitation. J. Korean Phys. Soc. 2016, 69 (4), 584-588. https://doi.org/10.3938/jkps.69.584.

(29) Salavati-Niasari, M.; Mahmoudi, T.; Sabet, M.; Hosseinpour-Mashkani, S. M.; Soofivand, F.; Tavakoli, F. Synthesis and Characterization of Copper Ferrite Nanocrystals via Coprecipitation. J. Clust. Sci. 2012, 23 (4), 1003-1010. https://doi.org/10.1007/s10876-012-0486-7.

(30) Calvo-de la Rosa, J.; Segarra, M. Optimization of the Synthesis of Copper Ferrite Nanoparticles by Polymer-Assisted Sol-Gel Method. ACS Omega 2019, 4 (19), 1828918298. https://doi.org/10.1021/acsomega.9b02295.

(31) Yadav, R. S.; Havlica, J.; Masilko, J.; Kalina, L.; Wasserbauer, J.; Hajdúchová, M.; Enev, V.; Kuřitka, I.; Kožáková, Z. Cation Migration-Induced Crystal Phase Transformation in Copper Ferrite Nanoparticles and Their Magnetic Property. $J$. Supercond. Nov. Magn. 2016, 29 (3), 759-769. https://doi.org/10.1007/s10948-0153339-4.

(32) Desai, M.; Prasad, S.; Venkataramani, N.; Samajdar, I.; Nigam, A. K.; Krishnan, R. Annealing Induced Structural Change in Sputter Deposited Copper Ferrite Thin Films and Its Impact on Magnetic Properties. J. Appl. Phys. 2002, 91 (3), 2220-2227. https://doi.org/10.1063/1.1433176.

(33) Sumangala, T. P.; Mahender, C.; Barnabe, A.; Venkataramani, N.; Prasad, S. Structural, Magnetic and Gas Sensing Properties of Nanosized Copper Ferrite Powder Synthesized by Sol Gel Combustion Technique. J. Magn. Magn. Mater. 2016, 418, 48-53. https://doi.org/10.1016/j.jmmm.2016.02.053.

(34) Zhuravlev, V. A.; Minin, R. V.; Itin, V. I.; Lilenko, I. Y. Structural Parameters and Magnetic Properties of Copper Ferrite Nanopowders Obtained by the Sol-Gel Combustion. J. Alloys Compd. 2017, 692, 705-712. https://doi.org/10.1016/j.jallcom.2016.09.069.

(35) Khemthong, P.; Kongmark, C.; Kochaputi, N.; Mahakot, S.; Rodporn, S.; Faungnawakij, K. In Situ X-Ray Absorption Fine Structure Probing-Phase Evolution of CuFe2O4 in Nanospace Confinement. Inorg. Chem. 2019, 58 (10), 6584-6587. https://doi.org/10.1021/acs.inorgchem.9b00540.

(36) Rashad, M. M.; Mohamed, R. M.; Ibrahim, M. a.; Ismail, L. F. M.; Abdel-Aal, E. a. Magnetic and Catalytic Properties of Cubic Copper Ferrite Nanopowders Synthesized from Secondary Resources. Adv. Powder Technol. 2012, 23 (3), 315-323. https://doi.org/10.1016/j.apt.2011.04.005.

(37) Slimani, Y.; Güngüneş, H.; Nawaz, M.; Manikandan, A.; El Sayed, H. S.; Almessiere, M. A.; Sözeri, H.; Shirsath, S. E.; Ercan, I.; Baykal, A. Magneto-Optical and Microstructural Properties of Spinel Cubic Copper Ferrites with Li-Al Co-Substitution. Ceram. Int. 2018, 44 (12), 14242-14250. https://doi.org/10.1016/j.ceramint.2018.05.028.

(38) Xing, Z.; Ju, Z.; Yang, J.; Xu, H.; Qian, Y. One-Step Solid State Reaction to Selectively 
Fabricate Cubic and Tetragonal CuFe2O4 Anode Material for High Power Lithium Ion Batteries. Electrochim. Acta 2013, 102, 51-57. https://doi.org/10.1016/j.electacta.2013.03.174.

(39) Tang, X.-X.; Manthiram, A.; Goodenough, J. B. Copper Ferrite Revisited. J. Solid State Chem. 1989, 79 (2), 250-262. https://doi.org/10.1016/0022-4596(89)90272-7.

(40) Nedkov, I.; Vandenberghe, R. E.; Marinova, T.; Thailhades, P.; Merodiiska, T.; Avramova, I. Magnetic Structure and Collective Jahn-Teller Distortions in Nanostructured Particles of CuFe 2 O 4. Appl. Surf. Sci. 2006, 253 (5), 2589-2596. https://doi.org/10.1016/j.apsusc.2006.05.049.

(41) Nikolić, V. N.; Vasić, M. M.; Kisić, D. Observation of C-CuFe2O4 Nanoparticles of the Same Crystallite Size in Different Nanocomposite Materials: The Influence of Fe3+ Cations. J. Solid State Chem. 2019, 275 (April), 187-196. https://doi.org/10.1016/j.jssc.2019.04.007.

(42) Rashad, M. M.; Soltan, S.; Ramadan, A. A.; Bekheet, M. F.; Rayan, D. A. Investigation of the Structural, Optical and Magnetic Properties of $\mathrm{CuO} / \mathrm{CuFe} 2 \mathrm{O} 4$ Nanocomposites Synthesized via Simple Microemulsion Method. Ceram. Int. 2015, 41 (9), 12237-12245. https://doi.org/10.1016/j.ceramint.2015.06.046.

(43) Constantinides, G.; Ulm, F. J.; Van Vliet, K. On the Use of Nanoindentation for Cementitious Materials. Mater. Struct. Constr. 2003, 36 (257), 191-196. https://doi.org/10.1617/14020.

(44) Constantinides, G.; Ravi Chandran, K. S.; Ulm, F. J.; Van Vliet, K. J. Grid Indentation Analysis of Composite Microstructure and Mechanics: Principles and Validation. Mater. Sci. Eng. A 2006, 430 (1-2), 189-202. https://doi.org/10.1016/j.msea.2006.05.125.

(45) Constantinides, G.; Ulm, F. J. The Nanogranular Nature of C-S-H. J. Mech. Phys. Solids 2007, 55 (1), 64-90. https://doi.org/10.1016/j.jmps.2006.06.003.

(46) Ulm, F. J.; Vandamme, M.; Bobko, C.; Alberto Ortega, J.; Tai, K.; Ortiz, C. Statistical Indentation Techniques for Hydrated Nanocomposites: Concrete, Bone, and Shale. $J$. Am. Ceram. Soc. 2007, 90 (9), 2677-2692. https://doi.org/10.1111/j.15512916.2007.02012.x.

(47) Sharifi, I.; Zamanian, A.; Behnamghader, A. Synthesis and Characterization of $\mathrm{Fe} 0.6 \mathrm{Zn} 0.4 \mathrm{Fe} 2 \mathrm{O} 4$ Ferrite Magnetic Nanoclusters Using Simple Thermal Decomposition Method. J. Magn. Magn. Mater. 2016, 412, 107-113. https://doi.org/10.1016/j.jmmm.2016.03.091.

(48) Lv, W.; Liu, B.; Luo, Z.; Ren, X.; Zhang, P. XRD Studies on the Nanosized Copper Ferrite Powders Synthesized by Sonochemical Method. Jorunal Alloy. Compd. 2008, 465 (3), 261-264. https://doi.org/10.1016/j.jallcom.2007.10.049.

(49) Tailhades, P.; Villette, C.; Rousset, A.; Kulkarni, G. U.; Kannan, K. R.; Rao, C. N. R.; Lenglet, M. Cation Migration and Coercivity in Mixed Copper-Cobalt Spinel Ferrite Powders. J. Solid State Chem. 1998, 141 (1), 56-63. https://doi.org/10.1006/jssc.1998.7914.

(50) Anandan, S.; Selvamani, T.; Prasad, G. G.; M. Asiri, A.; J. Wu, J. Magnetic and Catalytic Properties of Inverse Spinel CuFe 2 O 4 Nanoparticles. J. Magn. Magn. Mater. 2017, 432, 437-443. https://doi.org/10.1016/j.jmmm.2017.02.026. 


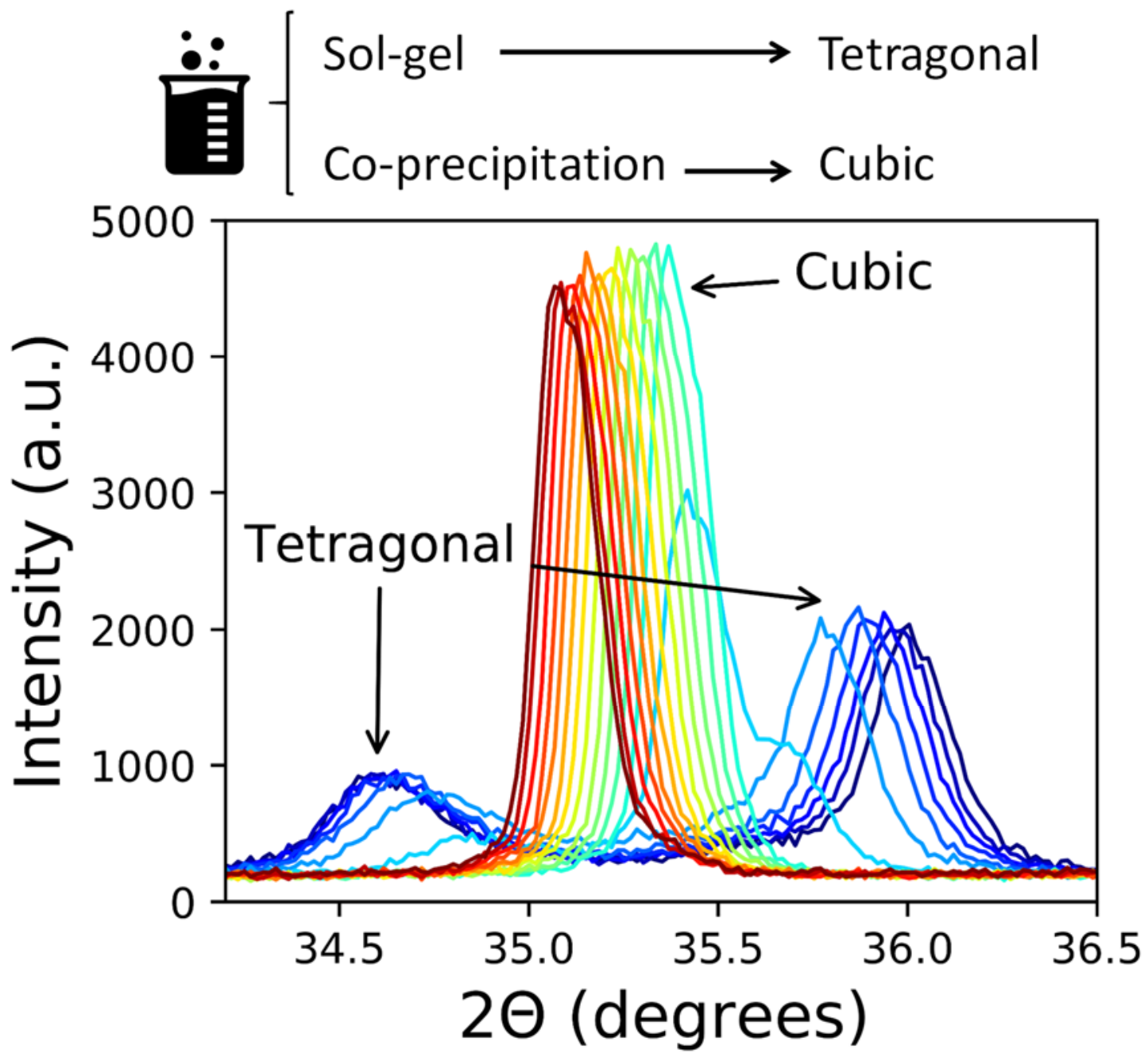

$\mathrm{CuFe}_{2} \mathrm{O}_{4}$ magnetic nanoparticles are synthetized under the same thermal conditions by sol-gel and co-precipitation methods, forming respectively the tetragonal and cubic structures. We analyse the chemical, structural, morphological and magnetic differences between the two products. Furthermore, this work provides a deep analysis on the formation of these crystal structures as a function of the synthesis route. The results suggest that their stability is determined by the specific cation distribution generated in the preliminary synthesis steps. 